\title{
Diabetes and Weight in Comparative Studies of Bariatric Surgery vs Conventional Medical Therapy: A Systematic Review and Meta-Analysis
}

\author{
G. Ribaric • J. N. Buchwald • T. W. McGlennon
}

Published online: 28 December 2013

(C) The Author(s) 2013. This article is published with open access at Springerlink.com

\begin{abstract}
We performed a meta-analysis of weight loss and remission of type 2 diabetes mellitus (T2DM) evaluated in randomized controlled trials (RCTs) and observational studies of bariatric surgery vs conventional medical therapy. English articles published through June 10, 2013 that compared bariatric surgery with conventional therapy and included T2DM endpoints with $\geq 12$-month follow-up were systematically reviewed. Body mass index (BMI, in kilogram per square meter), glycated hemoglobin $\left(\mathrm{HbA}_{1 \mathrm{C}}\right.$, in degree), and fasting plasma glucose (FPG, in milligram per deciliter) were analyzed by calculating weighted mean differences (WMDs) and pooled standardized mean differences and associated $95 \%$ confidence intervals $(95 \% \mathrm{CI})$. Aggregated T2DM remission event data were analyzed by calculating the pooled odds ratio (POR) and $95 \%$ CI. Random effects assumptions were applied throughout; $I^{2} \geq 75.0 \%$ was considered indicative of significant heterogeneity. Systematic review identified 512 articles: 47 duplicates were removed, 446 failed inclusion
\end{abstract}

Electronic supplementary material The online version of this article (doi:10.1007/s11695-013-1160-3) contains supplementary material, which is available to authorized users.

\section{G. Ribaric}

European Surgical Institute, Ethicon Endo-Surgery (Europe) GmbH, Hamburg, Germany

\section{J. N. Buchwald}

Division of Scientific Research Writing, Medwrite Medical

Communications, Maiden Rock, WI, USA

T. W. McGlennon

Statistical Analysis \& Quality of Life Assessment,

McGlennon MotiMetrics, Maiden Rock, WI, USA

G. Ribaric $(\bowtie)$

Ethicon Endo-Surgery (Europe) GmbH, MD\&D EMEA (Europe,

Middle East, Africa), Johnson \& Johnson, Hummelsbütteler

Steindamm 71, 22851 Norderstedt, Germany

e-mail: GRibaric@its.jnj.com criteria (i.e., $n<10$ per arm, animal studies, reviews, case reports, abstracts, and kin studies). Of 19 eligible articles, two not focused on diagnosed T2DM and one with insufficient T2DM data were excluded. In the final 16 included papers, 3,076 patients (mean BMI, 40.9; age, 47.0; 72.0\% female) underwent bariatric surgery; 3,055 (39.4; 48.6, $69.0 \%$ ) received conventional or no weight-loss therapy. In bariatric surgery vs conventional therapy groups, the mean $17.3 \pm 5.7$ month BMI WMD was 8.3 (7.0, 9.6; $p<0.001$; $\left.I^{2}=91.8\right), \mathrm{HbA}_{1 \mathrm{C}}$ was $1.1\left(0.6,1.6 ; p<0.001 ; I^{2}=91.9\right)$, and FPG, $24.9\left(15.9,33.9 ; p<0.001 ; I^{2}=84.8\right)$, with significant differences favoring surgery. The overall T2DM remission rate for surgery vs conventional group was 63.5 vs $15.6 \%$ $(p<0.001)$. The Peto summary POR was $9.8(6.1,15.9)$; inverse variance summary POR was $15.8(7.9,31.4)$. Of the included studies, $94.0 \%$ demonstrated a significant statistical advantage favoring surgery. In a meta-analysis of 16 studies (5 RCTs) with 6,131 patients and mean 17.3-month followup, bariatric surgery was significantly more effective than conventional medical therapy in achieving weight loss, $\mathrm{HbA}_{1 \mathrm{C}}$ and $\mathrm{FPG}$ reduction, and diabetes remission. The odds of bariatric surgery patients reaching T2DM remission ranged from 9.8 to 15.8 times the odds of patients treated with conventional therapy.

Keywords Bariatric $\cdot$ Metabolic $\cdot$ Comparative $\cdot$ Type 2 diabetes mellitus $\cdot$ T2DM $\cdot$ Systematic review .

Meta-analysis $\cdot$ Randomized controlled trial

\section{Introduction}

"Diabesity," a term coined by Dr. Ethan Sims in 1973 to denote comorbid obesity and type 2 diabetes mellitus (T2DM) [1], has steadily grown into a global epidemic. The World Health Organization (WHO) estimates the number of 
overweight adults at $>1.6$ billion and $>400$ million who are obese. By 2015, $>2.3$ billion adults are projected to be overweight with $>700$ million obese [2]. Globally, $>312$ million people suffer from T2DM [3], a disease associated with a markedly increased risk of heart disease and stroke, microand macrovascular consequences, retinopathy, and kidney failure [4]. While weight loss and its maintenance, by any means, aids in improving and managing T2DM [5, 6], longterm antidiabetic diet compliance is poor even when supported by pharmacotherapy; 50.0 to $90.0 \%$ of patients remain unable to achieve adequate diabetes control [7-9].

In the long-running, prospective, controlled Swedish Obese Subjects (SOS) study, weight loss by conventional medical therapy was associated with T2DM remission of approximately $21.0 \%(n=248)$ at 2 years (compared with $72.0 \%$ remission in postbariatric surgery patients $[n=342]$ ) and $12.0 \%(n=84)$ at 10 years (vs $37.0 \%$ bariatric surgery group remission $[n=118]$ ) [10], an approximately threefold difference in effective control of diabetes favoring bariatric surgery. Typically, when even excellent weight loss has been achieved by very low calorie diets (VLCDs) and intensive lifestyle programs, neither weight loss nor diabetes resolution has been maintained beyond 1-5 years [10-13] nor has diabetes resolved as rapidly as following most bariatric procedures (i.e., within days to a few weeks [14]). Several series suggest that although the weight-loss effect of bariatric surgery is attenuated in lower body mass index (BMI, in kilogram per square meter) patients $[15,16]$, surgery may achieve a higher rate of diabetes resolution than conventional medical therapy in patients who are only overweight (BMI $\geq 25-29.9$ ) through those with class III obesity (BMI $\geq 40.0)$ [17-19]. Diabetes and obesity are progressive, multifactorial diseases; it is probable that bariatric surgery and/or one of the emerging, less-invasive, endolumenal procedures in combination with life-long lifestyle modification may represent an optimum management strategy [11, 20, 21].

Procedures that most effectively reduce weight, such as Roux-en-Y gastric bypass (RYGB) and biliopancreatic diversion, realize 80.0 and $95.0 \%$ hyperglycemia remission, respectively [22], a markedly greater treatment effect than that seen in the majority of studies of conventional dietary and pharmacologic therapy; most patients fail to achieve the goal for glycemic control of $<7.0 \%$ glycated hemoglobin $\left(\mathrm{HbA}_{1 \mathrm{C}}\right)$ prescribed by the American Diabetes Association (ADA) [23, 24]. The etiology of diabetes remission following bariatric surgery is not fully understood. Remission may be engaged by divergent and/or additional mechanisms through bariatric surgery [25], as individual procedures reorganize the gastrointestinal (GI) tract differently, activating varied neurohormonal mechanisms [26, 27]. Preclinical [28] and clinical evidence [19, 29, 30] suggest that improved glycemic control is not linked exclusively with baseline weight or operative weight loss and results from complementary processes $[15,22,31-33]$.
Our aim was to assess diabetes and weight outcomes in comparative studies of bariatric surgery vs conventional medical therapy. In preliminary research, we found few directly comparative, level 1, randomized controlled trial (RCT) outcomes (as defined by the Oxford Centre for Evidence-Based Medicine [34]). As a result, we broadened our inclusion criteria to incorporate directly comparative observational studies (OSs). Thus, the current review systematically identified and screened comparative studies of bariatric surgery vs conventional medical therapy in adults with a mean $\mathrm{BMI} \geq 25$ and subjected the aggregated weight and diabetes data (BMI, $\mathrm{HbA}_{1 \mathrm{C}}$, fasting plasma glucose (FPG), and diabetes remission) to meta-analysis.

\section{Methods}

\section{Inclusion Criteria and Search Strategy}

An electronic literature search and cross-referencing of articles was performed within the following databases: National Library of Medicine PubMed ${ }^{\circledR} /$ MEDLINE $^{\circledR}$, SpringerLink ${ }^{\circledR}$, and SciVerse ${ }^{\circledR}$. The search strategy followed the identification and screening guidelines established by the Preferred Reporting Items for Systematic Reviews and Meta-Analyses (PRISMA) statement [35]. Articles were identified by Boolean combination of keywords: "bariatric surgery," "metabolic surgery," "diabetes surgery," "gastric band," "sleeve gastrectomy," "gastric bypass," "duodenal switch," "biliopancreatic diversion," with "medical treatment," "medical therapy," "conventional treatment," "conventional therapy," and "diet." An additional search using keyword phrases, "bariatric surgery, diabetes mellitus," and "bariatric surgery, glucose OR insulin OR $\mathrm{HbA}_{1 \mathrm{C}}$ or HOMA," was run. Limits set to govern the searches stipulated journal articles that featured comparative studies on adult human subjects written in the English language with no beginning date through June 10, 2013.

Compiled article citations were screened by title to exclude duplicates arising from unintentional collection of both e-publications and their follow-on print versions. The unique citations were evaluated by review of abstracts. Articles with $n<10$ in any study arm, reviews, animal studies, case reports, abstracts, book chapters, kin studies (i.e., reports with overlapping data, or outcomes reported for the same timeframe and/or by the same author group), and Comments or Letters to the Editor were excluded from eligibility. The remaining articles were read in full and assessed by two researchers to ensure that all or a subset of the overweight, mildly obese, or morbidly obese patients in each treatment arm had been diagnosed with T2DM (of any duration) prior to undergoing bariatric surgery or conventional therapy. Finally, articles evaluating fewer than one of the aforementioned T2DM endpoints were excluded from quantitative analysis. 


\section{Defining Diabetes Remission and Data Extraction}

The recommended glycemic goal for $\mathrm{HbA}_{1 \mathrm{C}}$ stipulated by the 2009 ADA Standards of Medical Care in Diabetes for adults is $<7.0 \%$ with a suggested normal range of 4.0-6.0\% [24]. A variety of definitions of T2DM remission have been used in bariatric surgery and conventional medical therapy studies. In the current analysis, the percentage of patients that achieved T2DM remission, as assessed independently in each included study, characterized T2DM remission rate.

Variable data of interest were extracted from included studies and entered into a dedicated database. Data collection objectives centered on study characteristics (including bariatric procedures, conventional treatments, study designs, and analysis time points); demographic and anthropometric measures (age, gender, BMI [weight (in kilogram), divided by height (in square meter)] [36]); markers of glycemic control ( $\mathrm{HbA}_{1 \mathrm{C}}$ and $\mathrm{FPG}$ ); and T2DM remission rate. Assessment of study quality indicated that a range of diverse medical therapies characterized the non-surgical control groups. In addition, certain studies combined outcome data from multiple bariatric surgery procedures and presented results in the form of a general surgery group vs conventional therapy; no stratification was used. The present authors opted to extend the concept of "grouping" to each study that met inclusion criteria; i.e., if studies reported on more than two arms (e.g., multiple surgery procedures and/or multiple forms of conventional therapy), data were pooled using weighted means and standard deviations to represent summary data for one "combined surgery group" vs one "combined conventional therapy group" per study.

\section{Statistical Analysis}

Data manipulation and analysis were conducted using SPSS ${ }^{\circledR}$ software, version 20.0 (IBM SPSS, Chicago, IL, USA) in conjunction with Comprehensive Meta Analysis 2.2 (Biostat, Englewood, NJ, USA). Body mass index, $\mathrm{HbA}_{1 \mathrm{C}}$, and FPG were analyzed by calculating weighted mean differences (WMDs) and pooled standardized mean differences (SMDs) and associated $95 \%$ confidence intervals (CI). Aggregated T2DM remission event data were analyzed by calculating the pooled odds ratio (POR) and $95 \%$ CI. Random effects assumptions were applied throughout; $P \geq$ $75.0 \%$ was considered indicative of significant heterogeneity. [See Electronic Supplementary Material, Appendix 1 including references $37-40$ for detailed statistical methodology.]

\section{Results}

\section{Study Characteristics}

The results of the systematic review are presented in Fig. 1. A total of 512 articles were identified by extensive electronic database search. Forty-seven duplicates were removed. After screening 465 unique citations by title and abstract, 446 failed to meet inclusion criteria and were excluded. The remaining 17 articles were read and assessed for eligibility. Two that provided neither primary nor secondary outcomes related to patients with diagnosed T2DM and one that provided insufficient T2DM data to assess at the 12-month analysis time point were excluded, leaving a final set of 16 articles [41-56] for quantitative analysis.

Characteristics of included studies are described in Table 1. Comparative articles were published over a slightly less than 10-year span, between December 23, 2004 and June 10, 2013, the majority $(13 / 16,81.3 \%)$ in the last 3.5 years. The respective country of origin (based on first author's affiliation) and article distribution was: USA, six (38.0\%); Italy, four (25.0\%); Australia, two (12.5\%); Norway, two (12.5\%); Sweden, one (6.0\%); and Korea, one (6.0\%). Study designs included 5 (31.0\%) nonblinded RCTs, 11 OSs, 3 (19.0\%) nonrandomized controlled trials (nRCTs), 5 (31.0\%) prospective comparison studies, and $3(19.0 \%)$ retrospective database reviews. All studies obtained local institutional or ethics review board protocol approval, 12 mentioned obtaining informed consent, and 8 were nationally registered as clinical trials. Often, more than one WHO weight class was studied in a report: 11 (69.0\%) included morbidly obese patients, 4 (25.0\%) obese, 5 (31.3\%) mildly obese, and 1 (6.3\%) overweight. Our analysis focused on results collected between 12 and 24 months following study commencement. Mean follow-up was $17.3 \pm$ 5.7 months (median 15.0 months). T2DM remission was defined variably across studies; however, the target criteria was always identical for the two arms within each individual study.

Bariatric surgical procedures employed were wellaccepted, frequently performed operations [57]: Roux-en-Y gastric bypass $(11 ; 69.0 \%)$, laparoscopic adjustable gastric banding (LAGB; 5, $25.0 \%$ ), biliopancreatic diversion (BPD; 3, 18.8\%), laparoscopic sleeve gastrectomy (LSG; 3, 18.8\%), vertical banded gastroplasty (VBG; 1, $6.3 \%$ ), and duodenal switch (DS; 1, $6.3 \%$ ). Conventional therapies ranged from intensive weight loss programs with initial VLCDs graduating to moderate calorie intake combined with lifestyle modification training and diabetologist-managed T2DM treatment; to those with structured, rehabilitative inpatient programs; some that included routine medical management of T2DM and selfmonitored weight-loss and exercise plans; to a few programs with no educational plan or dietary supervision.

\section{Preliminary Analysis of RCTs vs OSs}

Analysis of variance using pooled summary data indicated no statistically significant baseline differences between RCT surgery, RCT conventional, OS surgery, and OS conventional patient groups with respect to age ((mean [SE]) (45.8 [2.0], 47.1 [1.4], 46.6 [2.0], 49.7 [1.4]), respectively; $F(3,6,127)=$ 
Fig. 1 Outcomes of the systematic review of the literature by record identification, screening, and analysis in the Preferred Reporting Items for Systematic Reviews and Meta-Analyses (PRISMA) statement flow diagram

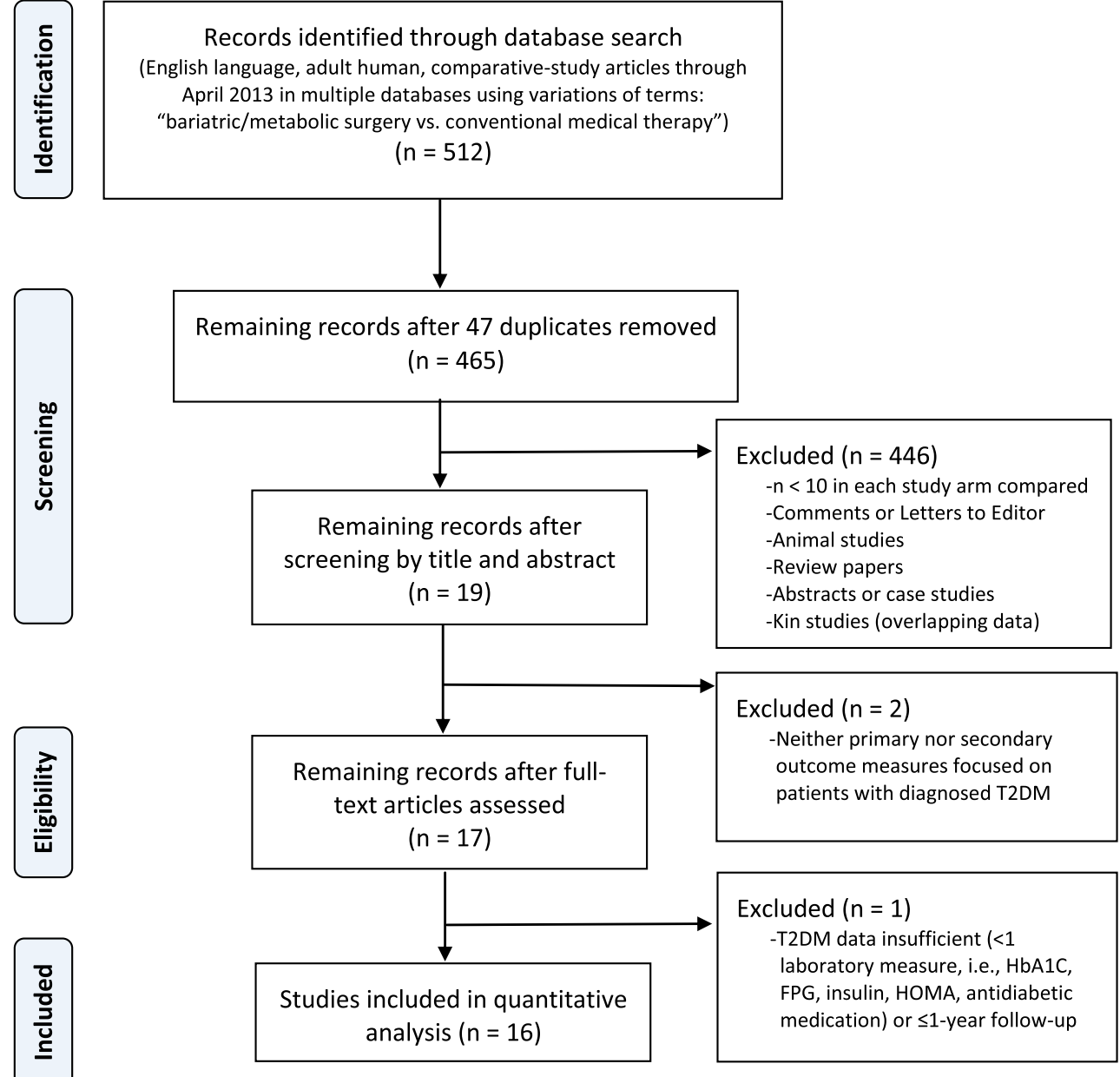

0.83, $p=0.50)$, BMI ((37.5 [1.7], 42.5 [1.2], 37.2 [1.8], 40.3 $[1.2]) ; F(3,6,127)=1.23, p=0.30, \mathrm{HbA}_{1 \mathrm{C}}(8.9[0.6], 7.6[0.4]$, $7.8[0.6], 7.1[0.4]) ; F(3,1,517)=1.84, p=0.14)$, and FPG (163.0 [8.7], 136.3 [7.9], 156.1 [11.7], 134.0 [10.43]); $F(3,4,926)=0.52(p=0.67)$. In light of these findings, data were integrated from RCTs and OSs to make direct comparisons between bariatric surgery and conventional therapy groups at baseline.

\section{Patient Characteristics and Baseline Clinical Profile}

The total number of patients in the included studies was 6,131 ; 3,076 underwent bariatric surgery and 3,055 underwent conventional treatment. The mean age of patients included in this meta-analytic research was 47.8 years, ranging from 35.8 to 62.0 years. Relative to the conventional treatment group (CTG), the bariatric surgery group (BSG) was slightly younger $(47.0$ years [ $95 \% \mathrm{CI}, 45.3,48.7]$ vs 48.6 years [46.6, 50.7]; pooled $\mathrm{SMD}=-0.23[-0.28,-0.18], p<0.05 ; I^{2}=$ $0.0 \%$ ), and was comprised of a somewhat greater percentage of females (72.0 vs $69.0 \%, p<0.01)$. Overall baseline comparability statistics for select clinical variables (i.e., BMI [mean data available on 16 studies/100\%], $\mathrm{HbA}_{1 \mathrm{C}}$ [12/75\%], and FPG [11/69\%]) are presented in Table 2. The summary statistics indicated that, on average and relative to the CTG, BSG patients had a higher mean baseline BMI $\left(40.9 \mathrm{~kg} / \mathrm{m}^{2}[38.5,43.3] \mathrm{vs} 39.4 \mathrm{~kg} / \mathrm{m}^{2}\right.$ [37.3, 41.6]; pooled $\mathrm{SMD}=0.33[0.16,0.51], p<0.001 ; I^{2}=84.0 \%$ ), a higher $\mathrm{HbA}_{1 \mathrm{C}}$ level $(8.0 \%[7.1,9.0]$ vs $7.7 \%[6.8,8.5]$; pooled $\mathrm{SMD}=0.39[0.12,0.67], p<0.01 ; I^{2}=84.0 \%$ ), and a higher FPG level $(150.3 \mathrm{mg} / \mathrm{dL}[135.7,164.9]$ vs $143.1 \mathrm{mg} / \mathrm{dL}[129.8$, 156.3]; pooled $\mathrm{SMD}=0.15[0.02,0.28], p<0.05 ; I^{2}=84.0 \%$ ). These data suggest that the BSG and the CTG were fairly wellmatched at baseline along variables relevant to the study of T2DM remission. The mean SMD characterizing baseline differences was $0.28(0.15-0.39)$, a value considered to represent a "small" statistical and clinical mean difference between groups and an approximate distribution overlap of $80.0-85.0 \%$.

Assessment of Within-Group Change in Clinical Markers After Treatment

Table 3 presents meta-analytic data summarizing mean baseline (pretreatment), mean follow-up (post-treatment), and 

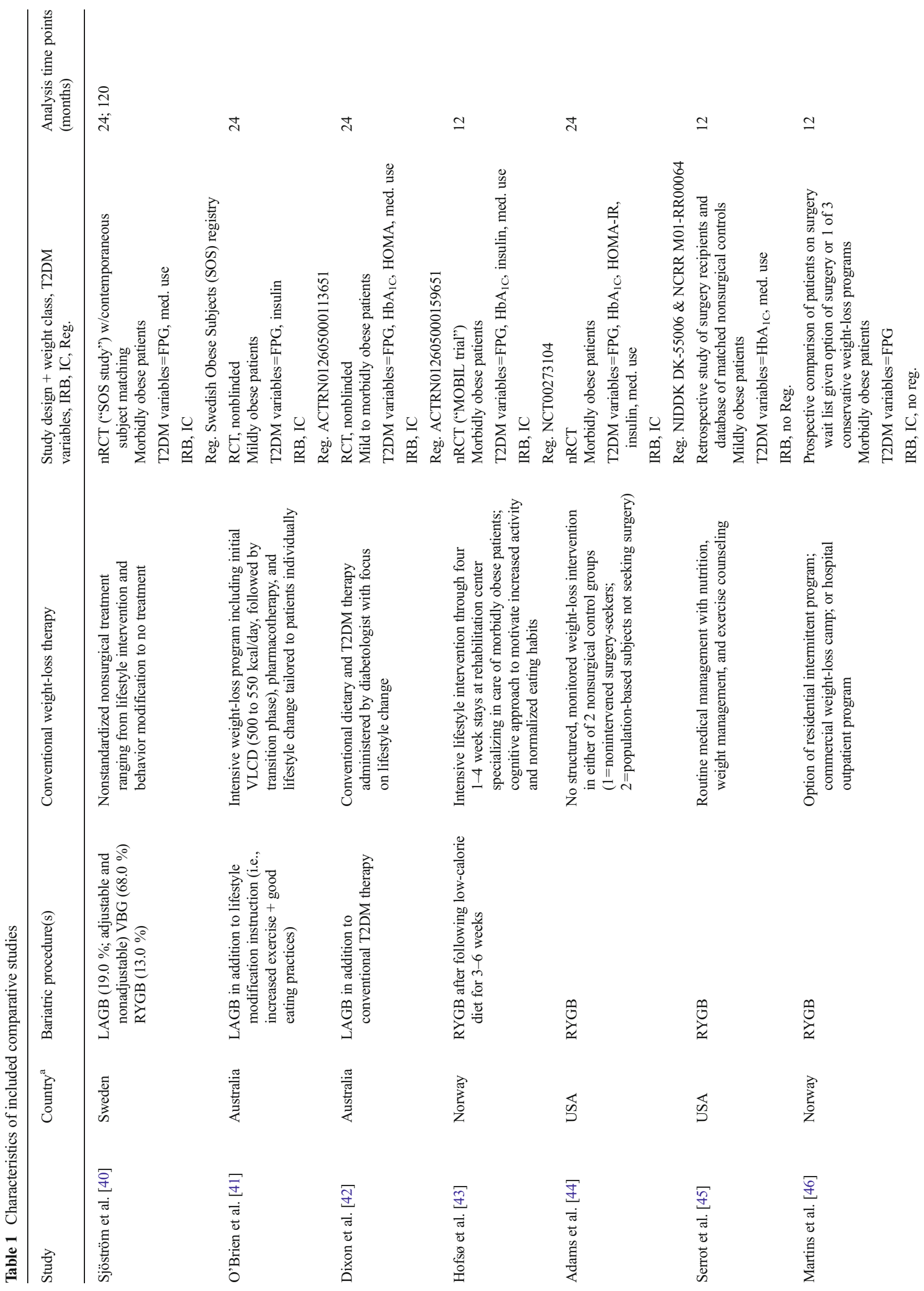


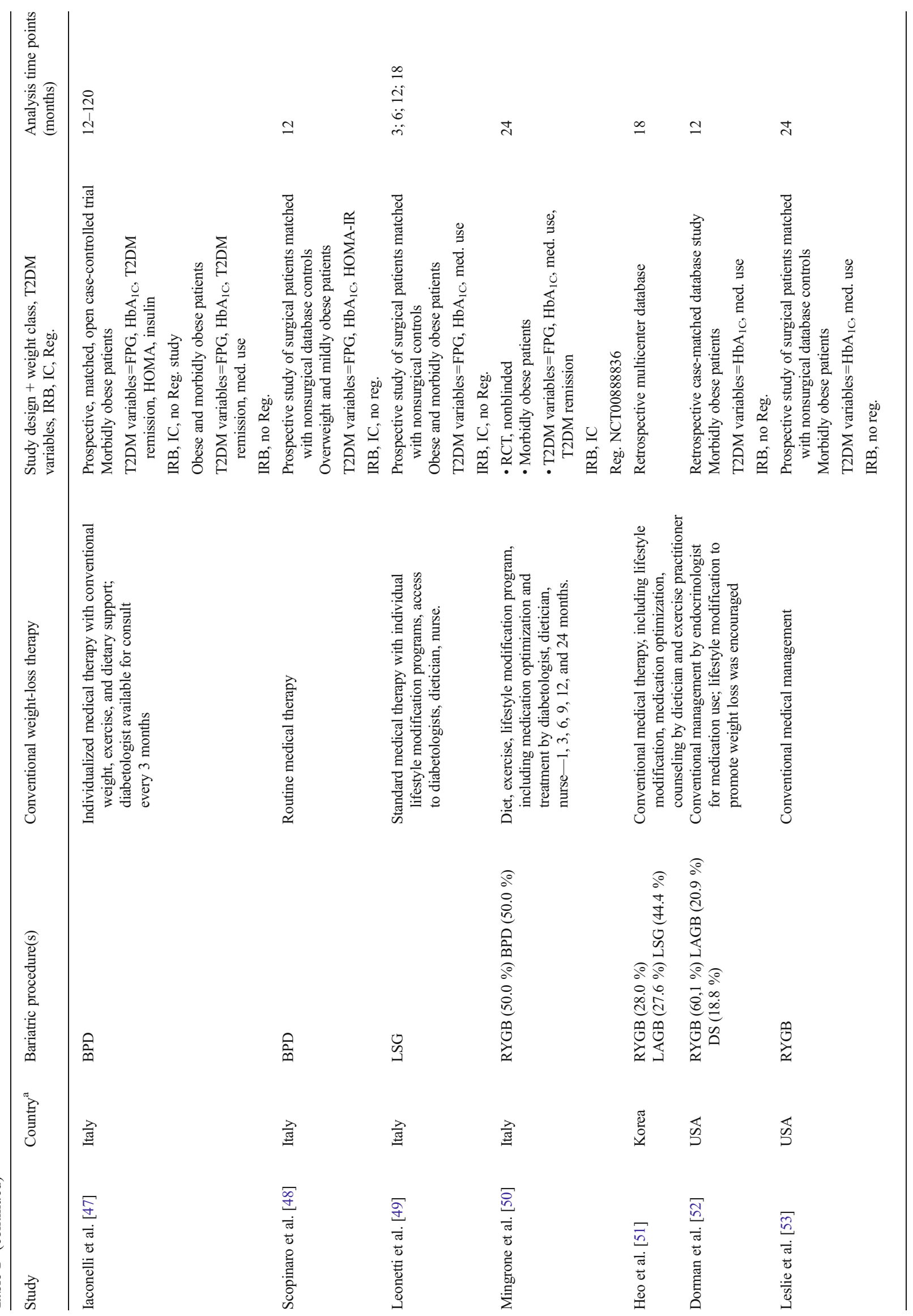




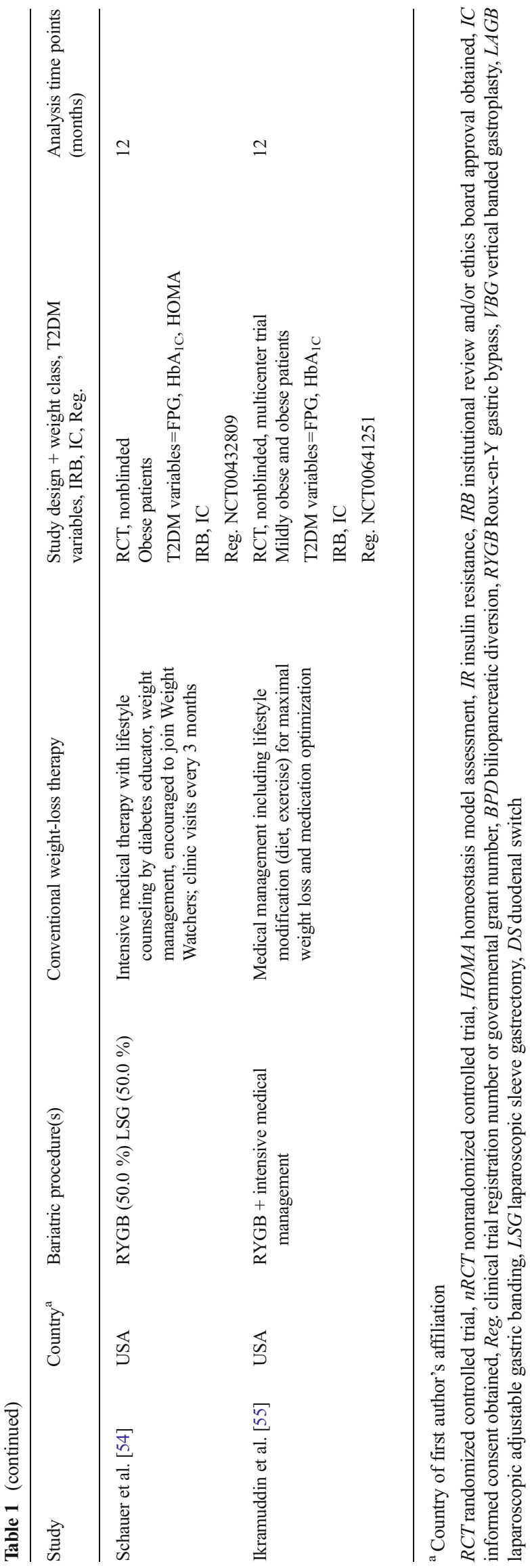

mean change values in $\mathrm{BMI}, \mathrm{HbA}_{1 \mathrm{C}}$, and FPG for each of the studies within the two treatment groups (i.e., BSG and CTG). Pooled estimates of overall means and mean change (WMD) are also provided. The weighted mean baseline BMI for the BSG was $40.9 \mathrm{~kg} / \mathrm{m}^{2}$ (95\% CI, 38.5, 43.3), with a follow-up weighted mean BMI of $29.4 \mathrm{~kg} / \mathrm{m}^{2}(27.8,30.9)$. The WMD in BMI for BSG patients was $11.4 \mathrm{~kg} / \mathrm{m}^{2}$ ([95 \% CI, 10.0, 12.9], statistical significance of overall effect: $p<0.001, I^{2}=95.0 \%$ ). In contrast, the weighted mean baseline BMI for the CTG was $39.4 \mathrm{~kg} / \mathrm{m}^{2}(37.3,41.6)$, with a follow-up weighted mean BMI of $37.8 \mathrm{~kg} / \mathrm{m}^{2}$ (35.6, 39.9). The WMD for all patients undergoing some form of conventional therapy was $1.6 \mathrm{~kg} / \mathrm{m}^{2}([0.7,2.6], p<0.01$, $I^{2}=86.5 \%$ ).

Within-group mean changes in $\mathrm{HbA}_{1 \mathrm{C}}$ and FPG tended to follow the pattern of change observed in BMI. At baseline, the BSG had a weighted mean $\mathrm{HbA}_{1 \mathrm{C}}$ of $8.0 \%(7.1,9.0)$, with a follow-up of $6.1 \%(5.8,6.4)$, a reduction that represented an overall WMD of $2.0 \%\left([1.2,2.8], p<0.001, I^{2}=86.5 \%\right)$ for BSG patients. The CTG was found to have a weighted mean baseline $\mathrm{HbA}_{1 \mathrm{C}}$ of $7.7 \%(6.8,8.5)$, with a follow-up of $7.2 \%$ $(6.6,7.7)$. The WMD in $\mathrm{HbA}_{1 \mathrm{C}}$ levels following conventional therapy was $0.47 \%\left([0.1,0.9], p<0.05 ; I^{2}=90.1 \%\right)$. Similarly, the BSG had a baseline weighted mean FPG of $150.3 \mathrm{mg} /$ $\mathrm{dL}(135.7,164.9)$, with a follow-up of $95.3 \mathrm{mg} / \mathrm{dL}$ (89.3, 101.3). The WMD was $53.3 \mathrm{mg} / \mathrm{dL}$ ([40.0, 66.7], $p<0.001$; $\left.I^{2}=96.8 \%\right)$. Finally, baseline weighted mean FPG for the CTG was $143.1 \mathrm{mg} / \mathrm{dL}(129.8,156.3)$, with a follow-up of $123.2 \mathrm{mg} / \mathrm{dL}(113.3,133.1)$. The WMD in FPG levels for conventional therapy patients was $17.4 \mathrm{mg} / \mathrm{dL}$ ([8.8, 26.0], $p<0.001 ; I^{2}=89.2 \%$ ). Figures 2 and 3 depict trend lines characterizing the relative changes over time in BMI and $\mathrm{HbA}_{1 \mathrm{C}}$ levels for BSG and CTG groups stratified by study design.

\section{Assessment of Between-Group Differences in Clinical} Markers After Treatment

The WMD comparing BSG and CTG on follow-up BMI for combined OS data $(k=11 ; n=5,257)$ was $-8.5 \mathrm{~kg} / \mathrm{m}^{2}([-10.2$, -6.9 ], $\left.p<0.001 ; I^{2}=93.0 \%\right)$; whereas, the corresponding WMD for combined RCT data $(k=5 ; n=440)$ was $-7.7 \mathrm{~kg} / \mathrm{m}^{2}$ ([-10.1, -5.3], $\left.p<0.001 ; I^{2}=87.5 \%\right)$, with a high degree of $95 \%$ CI overlap. No significant heterogeneity $(Q p$ value $=0.573)$ was found between the OSs' summary estimate and the RCTs' summary estimate with respect to the magnitude and direction of treatment effect on BMI, with the surgery group favored in both study designs.

The WMD comparing BSG vs CTG on follow-up $\mathrm{HBA}_{1 \mathrm{C}}$, for combined OS data $(k=8 ; n=1,131)$ was $-0.89 \%$ $\left([-1.3,-0.45], p<0.001 ; r^{2}=91.7 \%\right)$; whereas, the corresponding WMD for combined RCT data $(k=4 ; n=370)$ was 


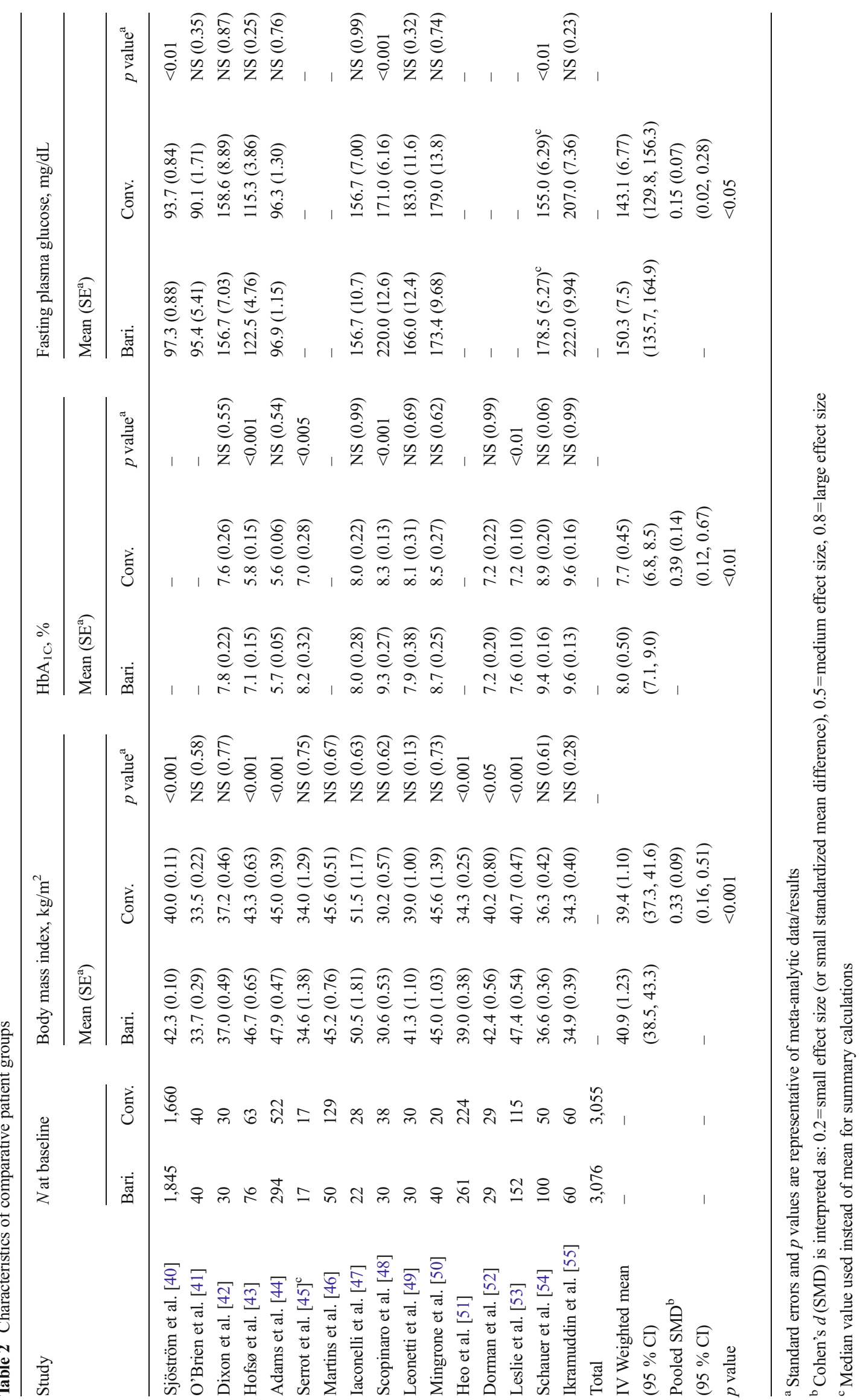




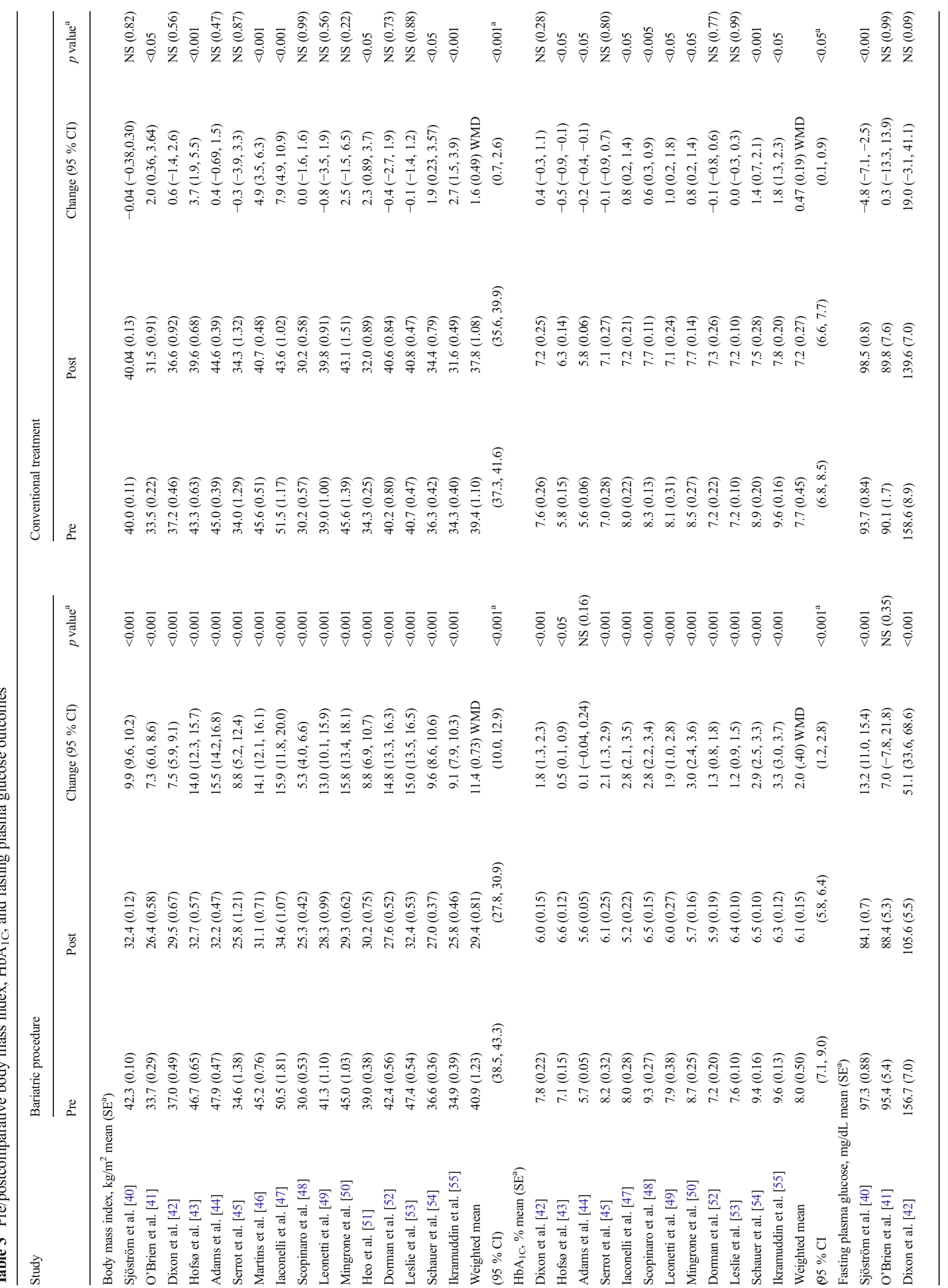




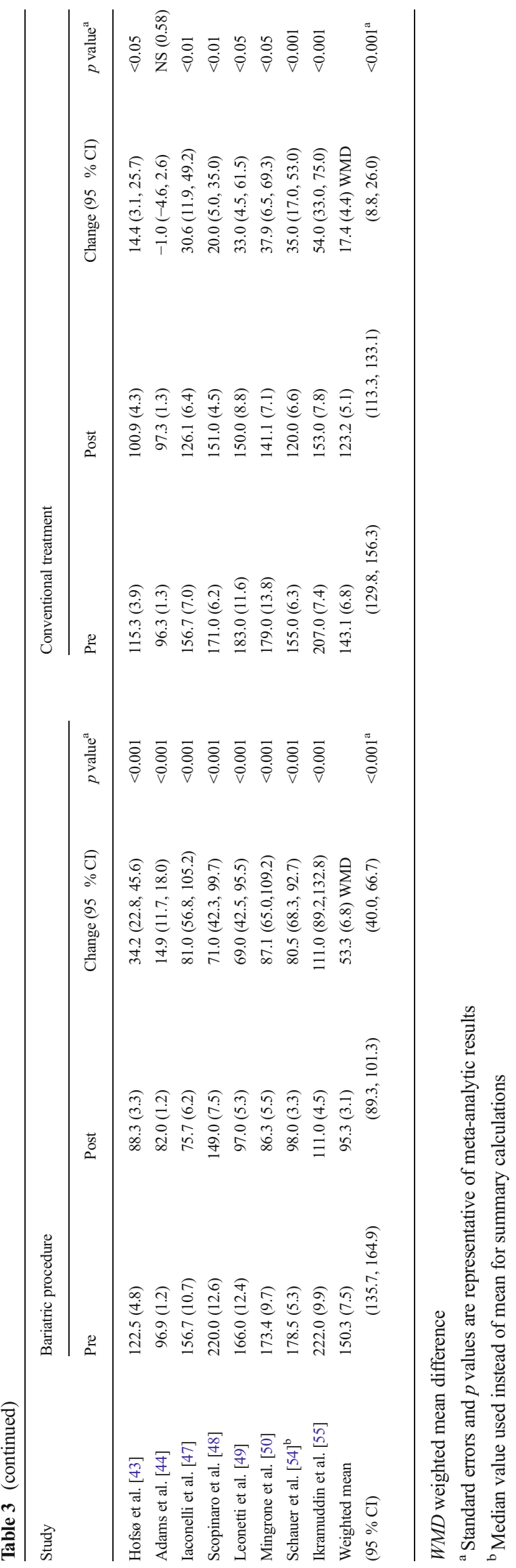

BMI Pre/Post

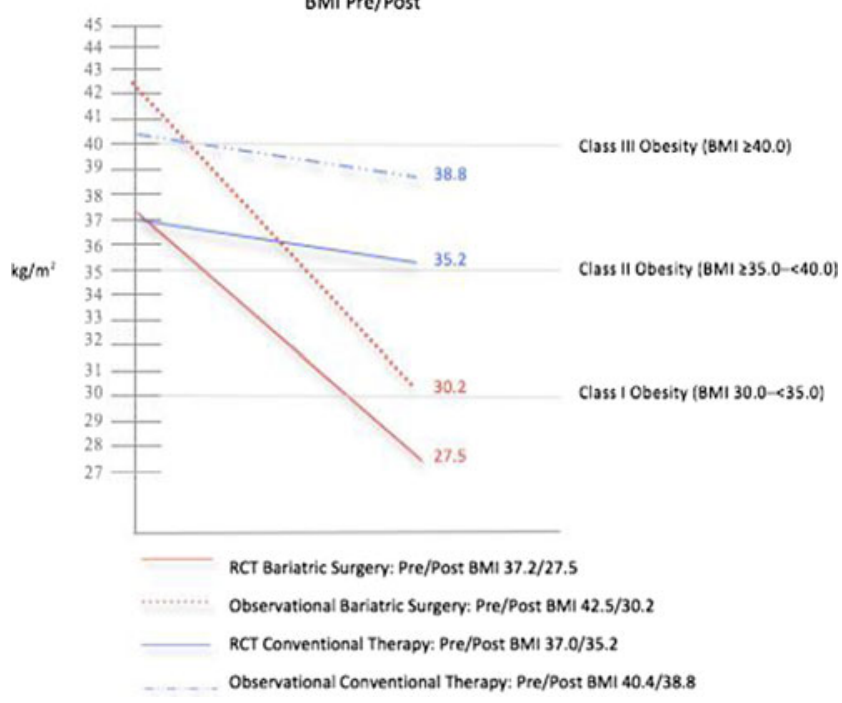

Fig. 2 Mean body mass index (BMI) reduction in bariatric surgery patients and conventional therapy patients by study design (randomized controlled trial vs observational)

$-1.43 \%\left([-2.1,-0.81], p<0.001 ; I^{2}=66.2 \%\right)$, with significant $95 \%$ CI overlap. No significant heterogeneity $(Q$ $p$ value $=0.16$ ) was found between the OSs' summary estimate and the RCTs' summary estimate with respect to the magnitude and direction of treatment effect on $\mathrm{HBA}_{1 \mathrm{C}}$, with the surgery group favored in both study designs.

The WMD comparing BSG vs CTG on follow-up FPG, for combined OS data $(k=6 ; n=4,460)$ was $-20.9 \mathrm{mg} / \mathrm{dL}([-29.3$, $\left.-12.5] ; p<0.001 ; I^{2}=84.3 \%\right)$; whereas, the corresponding WMD for combined RCT studies $(k=5 ; n=440)$ was $-30.1 \mathrm{mg} / \mathrm{dL}\left([-40.8,-19.5], p<0.001 ; I^{2}=80.5 \%\right)$, with a significant $95 \%$ CI overlap. No significant heterogeneity

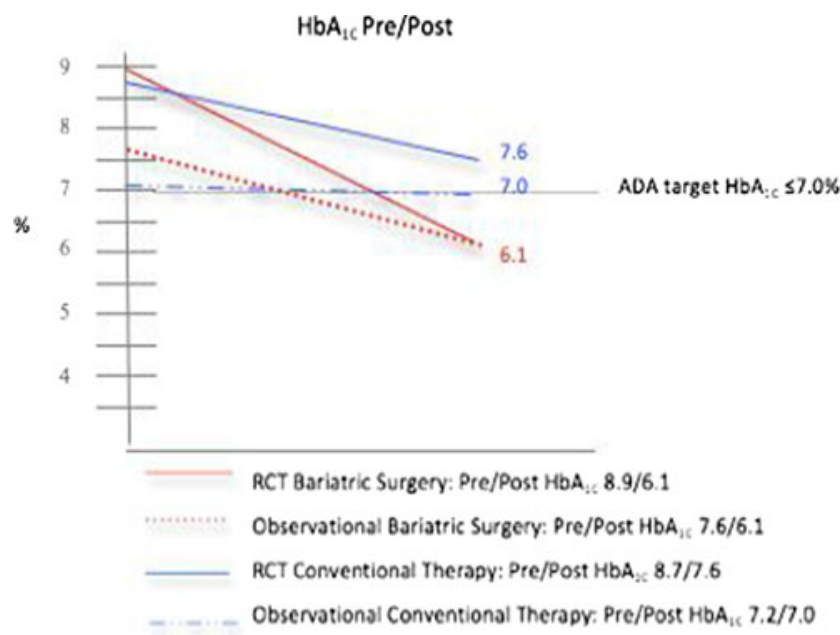

Fig. 3 Mean glycated hemoglobin $\left(\mathrm{HbA}_{1 \mathrm{C}}\right)$ reduction in bariatric surgery patients and conventional therapy patients by study design (randomized controlled trial vs observational) 
( $Q p$ value $=0.18)$ was found between the OSs' summary estimate and the RCTs' summary estimate with respect to the magnitude and direction of treatment effect on FPG, with the surgery group favored in both study designs.

In summary, independent treatment effect sizes for both OSs and RCTs were sufficiently concordant to permit estimation of an overall effect for each analysis presented in Fig. 4. The first three meta-analytic results (BMI, $\mathrm{HbA}_{1 \mathrm{C}}$, and $\mathrm{FPG}$ ) provide individual study mean follow-up differences and SEs, as well as independent summary estimates for OSs and RCTs, and the overall WMD for combined included studies. Negative mean difference values indicate a treatment effect favoring surgical intervention; OR results favored surgery over conventional therapy where values and plotting points comprising the forest chart are $>1.0$.

The overall $(k=16 ; n=5,697)$ between-group WMD characterizing BMI outcomes was $-8.3 \mathrm{~kg} / \mathrm{m}^{2}$ ([-9.6, -6.9], $p<0.001 ; I^{2}=91.8 \%$ ), favoring the surgery group. The corresponding pooled SMD was -1.62 ( $[-1.8,-1.4] ; p<0.001$; $I^{2}=90.1 \%$ ); adjusted effect size, $-1.95[-2.15,-1.76]$. Analysis of BMI using studies with complete data $(k=6$ studies, no imputation) yielded a WMD of $-9.5 \mathrm{~kg} / \mathrm{m}^{2}$ ([-12.3, -6.6], $\left.p<0.001 ; I^{2}=93.6 \%\right)$ and corresponding pooled SMD of $-2.1\left([-2.7,-1.6], p<0.001 ; I^{2}=85.2 \%\right)$.

WMD calculations summarizing between-group comparisons along the $\mathrm{HbA}_{1 \mathrm{C}}$ and FPG variable outcomes yielded similar results to those found for BMI. The overall $(k=12 ; n=$ 1,501) WMD for $\mathrm{HBA}_{1 \mathrm{C}}$ outcomes was $-1.1 \%([-1.6,-0.6]$, $p<0.001 ; I^{2}=91.9 \%$ ), again, favoring the surgery group. The corresponding pooled SMD was $-1.0([-1.4,-0.6], p<0.001$; $I^{2}=89.2 \%$; ; adjusted effect size, -1.39 ([-1.72, -1.01$\left.]\right)$. Analysis of $\mathrm{HbA}_{1 \mathrm{C}}$ using studies with complete data $(k=8$ studies, no imputation) yielded a WMD of $-1.3 \%([-1.54$, $\left.-0.98], p<0.001 ; I^{2}=65.6 \%\right)$ and pooled SMD of -1.13 $\left([-1.4,-0.8], p<0.001 ; I^{2}=73.2 \%\right)$.

Finally, the overall $(k=11 ; n=4,900)$ between-group FPG WMD was $-24.9 \mathrm{mg} / \mathrm{dL}([-33.9,-15.9] ; p<0.001$; $I^{2}=84.8 \%$ ), favoring the surgery group. The pooled SMD was $-0.71\left([-0.92,-0.50], p<0.001 ; I^{2}=80.5 \%\right.$; adjusted effect size, $-0.86[-1.05,-0.67])$. Analysis of FPG using studies with complete data $(k=5$ studies, no imputation) yielded a WMD of $-36.8 \mathrm{mg} / \mathrm{dL}([-56.3$, $-17.3], p<0.001 ; I^{2}=83.1 \%$ ) and pooled SMD of -0.96 $\left([-1.5,-0.5], p<0.001 ; I^{2}=79.9 \%\right)$.

Effects of Bariatric Surgery vs Conventional Therapy on $\%$ EWL and T2DM

Overall EWL means for the BSG and the CTG groups were $75.3 \%$ (57.2-94.6) and $11.3 \%$ (-5.7-29.8), respectively; overall T2DM remission rates were $63.5 \%(38.2-100.0)$ and $15.6 \%(0.0-46.7)(p<0.001$; Table 4$)$. Figure 5 presents a further breakdown of \%EWL and T2DM remission by treatment group and study design. Bariatric surgery patients enrolled in RCT designs reported the highest mean EWL $(80.0 \%)$; bariatric surgery patients enrolled in OSs had the highest $\mathrm{T} 2 \mathrm{DM}$ remission rate $(65.6 \%)$.

T2DM remission event data, PORs, and $95 \%$ CIs describing the effects of surgery vs conventional therapy on T2DM remission are presented in the final forest plot of Fig. 4. Independent summary estimates were calculated for RCTs and OSs using the Peto method. The POR and $95 \%$ CI for combined OS remission event data $(k=11 ; n=1,489)$ was 10.9 ([6.1, 19.5], $p<0.001 ; I^{2}=81.6 \%$ ); whereas, the corresponding POR and $95 \%$ CI for combined RCT remission event data $(k=5 ; n=404)$ was $7.8\left([3.3,18.4], p<0.001 ; I^{2}=70.2 \%\right)$, with a high degree of $95 \%$ CI overlap. No significant heterogeneity ( $Q p$ value $=0.52$ ) was found between the OSs' estimate and the RCTs' estimate with respect to the magnitude and direction of treatment effect on T2DM remission, with the surgery group favored in both study designs. Evaluation by $z$ score also indicated no statistically significant difference between OS and RCT summary estimates $(z=-0.57$; $p=0.57$; a $z$ score $\leq-1.96$ or $\geq 1.96$ would indicate a statistically significant difference at the 0.05 level). Thus, estimates were sufficiently concordant to calculate an overall effect (i.e., combining data from RCTs with OSs). As shown in Fig. 4, the $(k=16$; $n=1,893)$ summary POR was 9.8 ([6.1, 15.9], $p<0.001$; $\left.I^{2}=78.4 \%\right)$.

Independent PORs and $95 \%$ CIs were also calculated using the inverse variance method as a direct comparison to Peto findings. The POR and $95 \%$ CI for combined OS data was 18.9 ([8.1, 43.7], $p<0.001 ; I^{2}=79.9 \%$ ); whereas, the corresponding POR and $95 \% \mathrm{CI}$ for combined RCT data was $11.0\left([3.3,36.3], p<0.001 ; P^{2}=59.9 \%\right)$, with significant $95 \%$ CI overlap. No significant heterogeneity ( $Q p$ value $=$ 0.47) was found between the OS and RCT summary estimates, where the surgery group was favored in both study designs. Evaluation by $z$ score also indicated no statistically significant difference between the independent summary estimates $(z=-0.60 ; p=0.55)$, the inverse variance method yielded an overall summary POR of 15.8 ([7.9, 31.4], $p<0.001 ; I^{2}=75.2 \%$ ). Thus, according to the inverse variance method, the odds of T2DM remission in patients undergoing bariatric surgery were, on average, 15.8 times the odds of remission for those receiving conventional therapy. All but one of 16 studies indicated a clear statistical advantage favoring surgery.

Sensitivity and Subgroup Analyses

Three sensitivity analyses were performed: (1) an analysis excluding trials reporting no remission events; (2) an analysis excluding studies that combined data from multiple study arms; and (3) an analysis excluding all bariatric procedures 
BMI

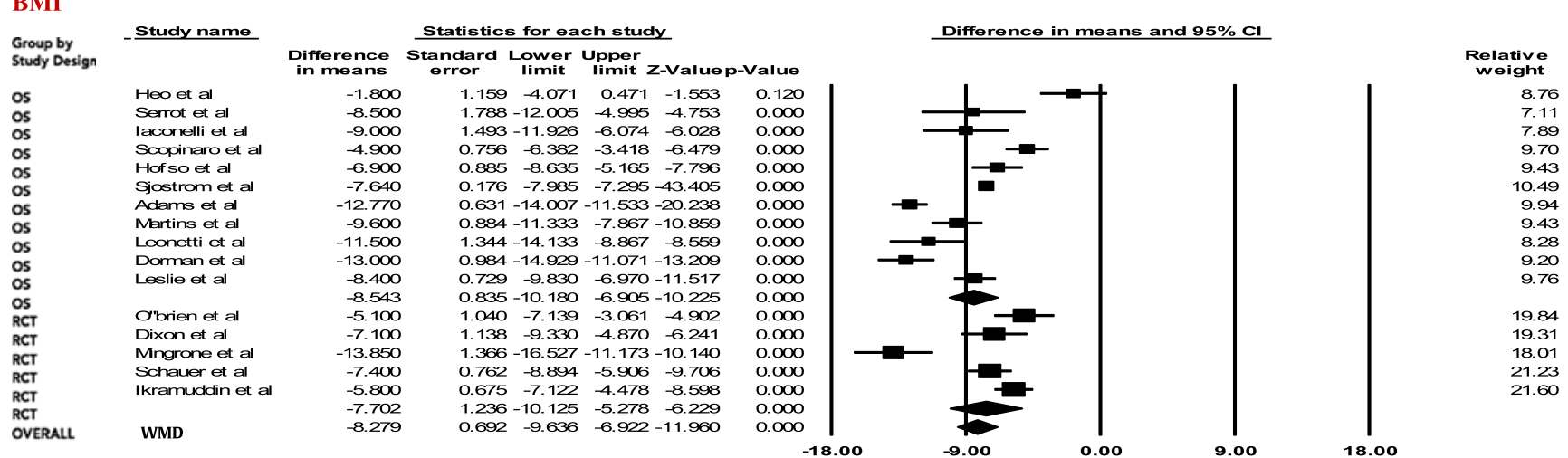

\begin{tabular}{|c|c|c|c|c|c|c|c|}
\hline \multirow{2}{*}{$\begin{array}{l}\text { HbA }_{1 C} \\
\text { Group } \\
\text { by study } \\
\text { design }\end{array}$} & \multirow[t]{2}{*}{ Study name } & \multicolumn{6}{|c|}{ Statistics for each study } \\
\hline & & $\begin{array}{l}\text { Difference } \\
\text { in means }\end{array}$ & $\begin{array}{l}\text { Standard } \\
\text { error }\end{array}$ & $\begin{array}{c}\text { Lower } \\
\text { limit }\end{array}$ & $\begin{array}{l}\text { Upper } \\
\text { limit }\end{array}$ & Z-Value & p-Value \\
\hline os & Hof so et al & 0.300 & 0.181 & -0.055 & 0.655 & 1.658 & 0.097 \\
\hline os & Serrot et al & -1.000 & 0.365 & -1.716 & -0.284 & -2.736 & 0.006 \\
\hline os & Adams et al & -0.250 & 0.082 & -0.412 & $2-0.088$ & -3.032 & 0.002 \\
\hline oS & Leonetti et al & -1.100 & 0.362 & -1.810 & -0.390 & -3.035 & 0.002 \\
\hline oS & Dorman et al & -1.400 & 0.319 & -2.026 & -0.774 & -4.382 & 0.000 \\
\hline oS & Leslie et al & -0.800 & 0.143 & -1.081 & -0.519 & -5.590 & 0.000 \\
\hline os & laconelli et al & -2.000 & 0.305 & -2.597 & -1.403 & -6.561 & 0.000 \\
\hline os & Scopinaro et al & -1.200 & 0. 182 & -1.557 & -0.843 & -6.590 & 0.000 \\
\hline OS & & -0.886 & 0.223 & -1.323 & $3-0.449$ & -3.976 & 0.000 \\
\hline RCT & Dixon et al & -1.210 & 0.295 & -1.787 & -0.633 & -4.107 & 0.000 \\
\hline RCT & Schauer et al & -1.000 & 0.239 & -1.467 & -0.533 & -4.193 & 0.000 \\
\hline RCT & Ikramuddin et al & -1.500 & 0.232 & -1.954 & -1.046 & -6.474 & 0.000 \\
\hline RCT & Mngrone et al & -2.000 & 0.256 & -2.501 & -1.499 & -7.822 & 0.000 \\
\hline RCT & & -1.428 & 0.316 & -2.048 & -0.809 & -4.521 & 0.000 \\
\hline OVERALL & WMD & -1.111 & 0.267 & -1.635 & -0.587 & -4.159 & 0.000 \\
\hline
\end{tabular}

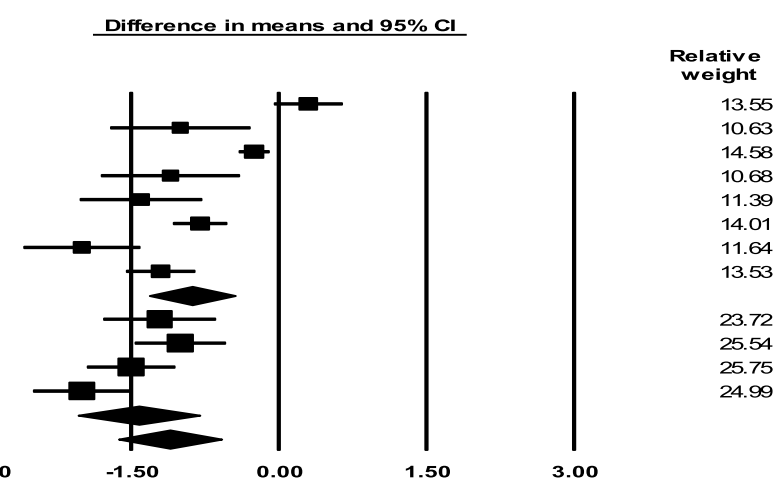

FPG

\begin{tabular}{|c|c|c|}
\hline $\begin{array}{l}\text { Group by } \\
\text { Stady Detign }\end{array}$ & $\underline{\text { Study name }}$ & $\begin{array}{l}\text { Difference } \\
\text { in means }\end{array}$ \\
\hline os & Scopinaro et al & -2.000 \\
\hline os & Hof so et al & -12.600 \\
\hline oS & Leonetti et al & -53.000 \\
\hline os & laconelli et al & -50.400 \\
\hline os & Adams et al & -15.280 \\
\hline os & Sjostrom et al & -14.400 \\
\hline os & & -20.869 \\
\hline RCT & OBrien et al & -1.400 \\
\hline RCT & Schaver et al & -22.000 \\
\hline RCT & Dixon et al & -34.000 \\
\hline RCT & Ikramuddin et al & -42.000 \\
\hline RCT & Mngrone et al & -54.800 \\
\hline RCT & & -30.118 \\
\hline OVERALL L T & WMD & -24.893 \\
\hline
\end{tabular}

Statistics for each study

Difference in means and $95 \% \mathrm{Cl}$

\begin{tabular}{|c|c|c|c|}
\hline $\begin{array}{l}\text { Idard } \\
\text { ror }\end{array}$ & $\begin{array}{c}\text { Lower } \\
\text { limit }\end{array}$ & $\begin{array}{l}\text { Upper } \\
\text { limit }\end{array}$ & 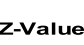 \\
\hline 8.383 & $3-18.430$ & 14.430 & -0.23 \\
\hline 5.361 & $1-23.106$ & -2.094 & -2.3 \\
\hline 10.239 & $9-73.068$ & -32.932 & \\
\hline 9.119 & -68.274 & -32.526 & \\
\hline 1.937 & -19.076 & -11.484 & -7.8 \\
\hline & & -12 & \\
\hline 4.296 & 5 -29.289 & -12.449 & -4.8 \\
\hline 8.973 & $3-18.987$ & 16.187 & -0.15 \\
\hline 6.65 & $1-35$ & -8.964 & -3 \\
\hline 8.888 & $3-51.419$ & -16.581 & -3.8 \\
\hline 9 & $9-59.67$ & -24.322 & -4.6 \\
\hline 9.375 & $5-73$. & -36.425 & -5.8 \\
\hline & 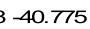 & -19.461 & \\
\hline & & -15 & \\
\hline
\end{tabular}
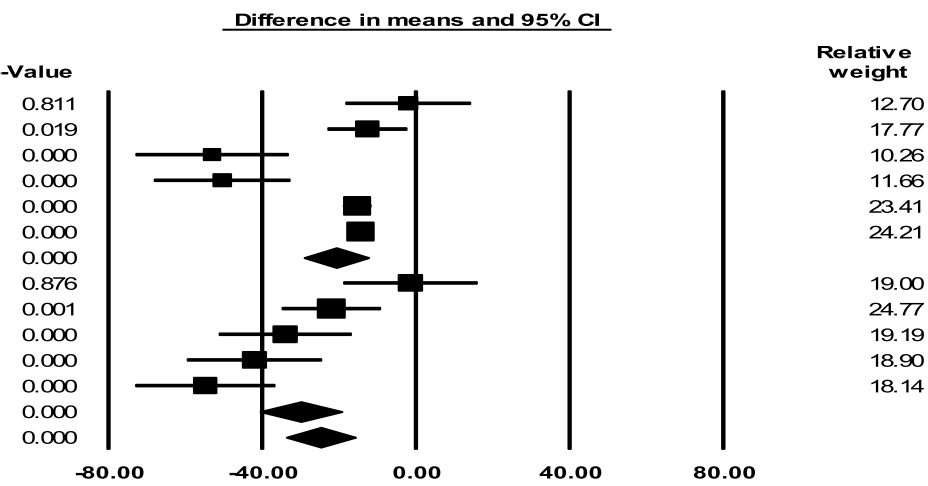

T2DM

remission

\begin{tabular}{|c|c|c|c|c|}
\hline \multirow{2}{*}{$\begin{array}{l}\text { Group by } \\
\text { Study Design }\end{array}$} & \multirow[t]{2}{*}{ Study name } & \multicolumn{3}{|c|}{ Statistics for each stud } \\
\hline & & $\begin{array}{c}\text { Peto } \\
\text { odds ratio }\end{array}$ & $\begin{array}{c}\text { Lower } \\
\text { limit }\end{array}$ & $\begin{array}{l}\text { Upper } \\
\text { limit }\end{array}$ \\
\hline os & Martins et al & 3.339 & 0.591 & 18.858 \\
\hline os & Hofso et al & 4.187 & 1.190 & 14.739 \\
\hline os & Leslie et al & 2720 & 1.598 & 4.628 \\
\hline os & Heo et al & 6.625 & 2.555 & 17.181 \\
\hline os & Serrot et al & 17.629 & 4.280 & 72.623 \\
\hline os & laconelli et al & 12.182 & 3.646 & 40.702 \\
\hline os & Dormen et al & 14.880 & 5.086 & 43.533 \\
\hline os & Leonetti et al & 26.517 & 9.520 & 73.857 \\
\hline os & Scopinaro et al & 34.185 & 12.760 & 91.582 \\
\hline os & Sjostromet al & 7.654 & 5.521 & 10.611 \\
\hline os & Adams et al & 38.944 & 19.685 & 77.045 \\
\hline os & & 10.900 & 6.104 & 19.462 \\
\hline RCT & O'Brien et al & 8.569 & 1.845 & 39.791 \\
\hline RCT & Schaver et $a$ & 3.501 & 1.603 & 7.647 \\
\hline RCT & Iframuddin et al & 3.719 & 1.721 & 8.036 \\
\hline RCT & Dixon et al & 11.053 & 4.015 & 30.429 \\
\hline $\mathrm{RCT}$ & Mingrone et al & 30.080 & 10.275 & 88.056 \\
\hline RCT & & 7.770 & 3.280 & 18.405 \\
\hline Oeve & 808 & 9.810 & 6.063 & 15.871 \\
\hline
\end{tabular}
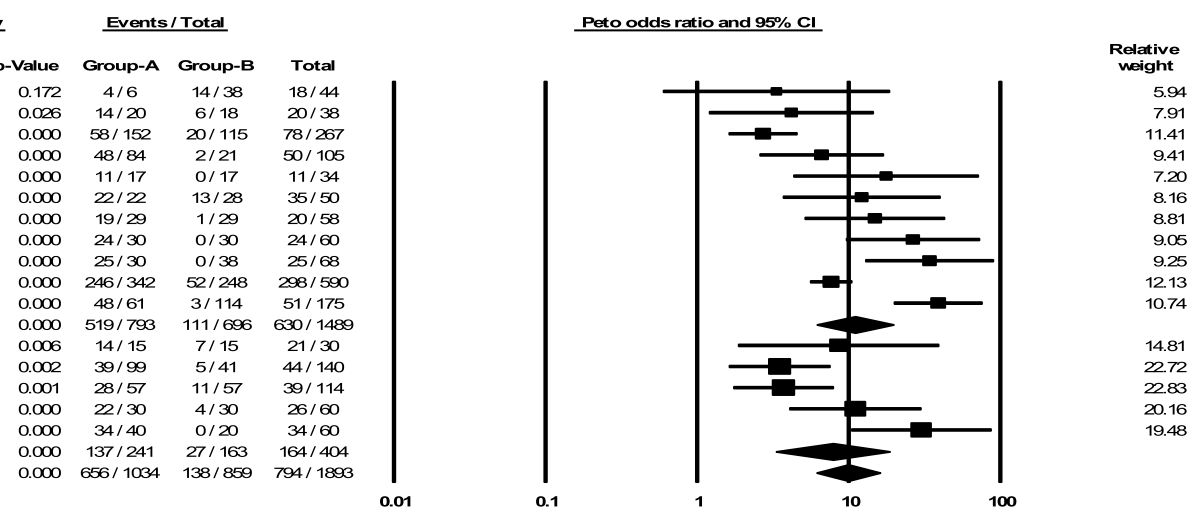

except RYGB (the most frequently performed procedure). [See Electronic Supplementary Material, Appendices 2 and
3 to read the detailed results of these subgroup analyses and an assessment of publication bias (includes Table 5 and Fig. 6).] 
Fig. 4 The first three tables and corresponding forest plots summarize meta-analyses of the relative effects of bariatric surgery vs conventional therapy on body mass index (BMI), glycated hemoglobin $\left(\mathrm{HbA}_{1 \mathrm{C}}\right)$, and fasting plasma glucose (FPG). Each study contributing to a particular meta-analysis is represented by a single darkened square contained on the forest plot; the size of the square being proportional to the amount of weight the study was given during the calculation of the pooled summary estimate. The pooled estimate in the first three analyses is expressed as the weighted mean difference (WMD) and is represented by the diamond shape at the base of each forest plot. Two additional diamonds in each forest plot represent independent summary estimates for observational studies and randomized controlled trials. Negative WMD values indicate a treatment effect favoring surgical intervention. The fourth table (and forest plot) represents an analysis of the relative effects of surgery vs conventional therapy on T2DM remission. In this case, the summary estimate of effect is given by the pooled odds ratio (POR). Results favor surgery over conventional therapy when odds ratio values are greater than one

\section{Discussion}

The current meta-analysis systematically identified and integrated a wide range of evidence regarding the effectiveness of bariatric surgery vs conventional therapy in promoting weight loss and T2DM remission. Results indicated that bariatric surgery demonstrated greater BMI reduction, greater reduction in $\mathrm{HbA}_{1 \mathrm{C}}$ and $\mathrm{FPG}$, and a much greater likelihood of $\mathrm{T} 2 \mathrm{DM}$ remission relative to patients receiving conventional therapy.

\section{Heterogeneity}

According to the prespecified $I^{2}$ value ( $\geq 75.0 \%$ ), a majority of meta-analyses undertaken in this study were characterized by significant heterogeneity (mean $I^{2}, 81.4 \%$ [0-96.8]; mean RCT, $I^{2}=72.0$; mean OS, $I^{2}=86.0$ ). Generally, when effect estimates from individual studies rest on opposite sides of the reference line (i.e., the point of no effect), study results are, by definition, heterogeneous, and conclusions questionable. However, the meta-analytic results presented in Fig. 4 showed the vast majority of estimated effects were consistently anchored on the same side of the reference line, with $95 \%$ CIs overlapping to a great extent. Thus, when viewed in isolation, the mean $I^{2}$ statistic may be somewhat misleading.

Table 4 Excess weight loss and diabetes remission

\begin{tabular}{|c|c|c|c|c|c|}
\hline \multirow[t]{3}{*}{ Study } & \multicolumn{2}{|l|}{$\% \mathrm{EWL}^{\mathrm{a}}$} & \multicolumn{3}{|l|}{$\mathrm{T} 2 \mathrm{DM}$ remission rate } \\
\hline & \multicolumn{2}{|l|}{ Mean } & \multicolumn{3}{|l|}{$\%(N)$} \\
\hline & Bariatric & Conventional & Bariatric & Conventional & $p$ value $^{\mathrm{b}}$ \\
\hline Sjöström et al. [40] & 57.2 & -0.3 & $72.0(342)$ & $21.0(248)$ & $<0.001$ \\
\hline O'Brien et al. [41] & 83.9 & 23.5 & $93.0(15)$ & $46.7(15)$ & $<0.01$ \\
\hline Dixon et al. [42] & 62.5 & 4.9 & $73.0(30)$ & $13.0(30)$ & $<0.001$ \\
\hline Hofsø et al. [43] & 64.5 & 20.2 & $79.0(14)$ & $0.0(6)$ & $<0.005$ \\
\hline Adams et al. [44] & 69.6 & 1.9 & $78.7(61)$ & $2.6(114)$ & $<0.001$ \\
\hline Serrot et al. [45] & 91.7 & 3.3 & $64.7(17)$ & $0.0(17)$ & $<0.001$ \\
\hline Martins et al. [46] & 69.8 & 23.8 & $67.0(6)$ & $36.8(38)$ & $\mathrm{NS}(0.17)$ \\
\hline Iaconelli et al. [47] & 62.4 & 29.8 & $100.0(22)$ & $45.0(28)$ & $<0.001$ \\
\hline Scopinaro et al. $[48]^{\mathrm{c}}$ & 94.6 & 0.0 & $83.0(30)$ & $0.0(38)$ & $<0.001$ \\
\hline Leonetti et al. [49] & 79.8 & -5.7 & $80.0(30)$ & $0.0(30)$ & $<0.001$ \\
\hline Mingrone et al. [50] & 79.0 & 12.1 & $85.0(40)$ & $0.0(20)$ & $<0.001$ \\
\hline Heo et al. [51] & 62.9 & 24.7 & $57.1(84)$ & $9.5(21)$ & $<0.001$ \\
\hline Dorman et al. [52] & 85.1 & -2.6 & $65.0(29)$ & $3.4(29)$ & $<0.001$ \\
\hline Leslie et al. [53] & 67.0 & -0.6 & $38.2(152)$ & $17.4(115)$ & $<0.001$ \\
\hline Schauer et al. [54] ${ }^{\mathrm{d}}$ & 82.8 & 16.8 & $39.4(99)$ & $12.0(41)$ & $<0.005$ \\
\hline Ikramuddin et al. [55] & 91.9 & 29.0 & $49.0(57)$ & $19.0(57)$ & $<0.001$ \\
\hline Overall & 75.3 & 11.3 & $63.5(1,028)$ & $15.6(847)$ & $<0.001$ \\
\hline (Range) & $(57.2-94.6)$ & $(-5.7-29.8)$ & $(38.2-100.0)$ & $(0.0-46.7)$ & \\
\hline
\end{tabular}

Negative values in the $\%$ EWL column denote mean weight gain

$E W L$ excess weight loss, T2DM type 2 diabetes mellitus

${ }^{\text {a }}$ Standardized calculation using BMI 25 as ideal weight constant

${ }^{\mathrm{b}} Z$ test for two population proportions

${ }^{\mathrm{c}}$ Patients with controlled diabetes following treatment included in remission rate calculation

${ }^{\mathrm{d}}$ Patients recovering from metabolic syndrome following treatment included in remission rate calculation 


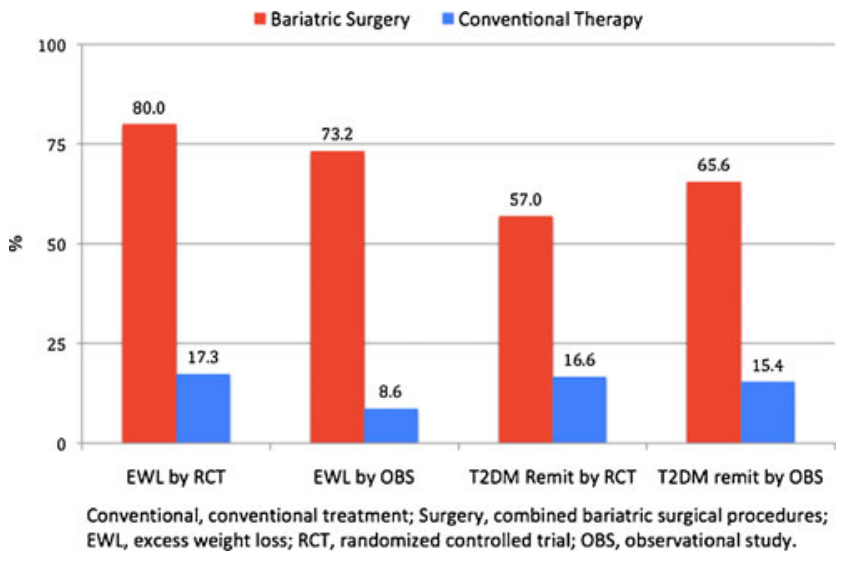

Fig. 5 Mean percent excess weight loss (\%EWL) in bariatric surgery patients and conventional therapy patients by study design type (randomized controlled trial vs observational)

One source of heterogeneity was expected as a result of integration of RCT and OS data. The majority of bariatric surgery studies are observational in design, as RCTs are less feasible to conduct for ethical and economic reasons [58]. Most RCTs are conducted in high-volume "centers of excellence" according to regulated protocols that conform to national guidelines [59,60]; therefore, RCT outcomes may differ significantly from OSs. Yet, interestingly, the current review's comparative analysis of trends in outcome variables, stratified by study design, was highly similar (Figs. 2, 3, and 5 [see Fig. 5 in online ESM 3]). In addition, meta-analytic results indicated no significant heterogeneity between RCT and OS summary estimates quantifying the relative effects of bariatric surgery vs conventional therapy on $\mathrm{BMI}, \mathrm{HbA}_{1 \mathrm{C}}$, and FPG reduction. In addition, both study designs demonstrated the superiority of bariatric surgery over conventional therapy in promoting T2DM remission. A common criticism of OSs, in general, is that they produce exaggerated effect sizes. While it is true that the POR for T2DM remission derived from OS studies was larger than that derived from RCTs (Peto, 10.9 $[6.1,19.5]$ vs $7.8[3.3,18.4]$; inverse variance, 18.9 [8.1, 43.7] vs $11.0[3.3,36.3])$, no significant heterogeneity was found between summary estimates. Further, Shrier et al., in their review of the principal elements underlying this claim, found that both study designs have strengths and weaknesses, and including OSs would increase precision appropriately, and may produce equally or more relevant and valid results [61].

\section{Weight}

\section{Conventional Treatment}

To place the current meta-analytic findings in context, they should be compared to publications outside of the included study set. The current findings in relation to BMI reduction (WMD $\left.1.6 \mathrm{~kg} / \mathrm{m}^{2}[0.7,2.6]\right)$ and EWL $(11.3 \%$ [-5.7-29.8]) after conventional treatment are similar to those of key systematic reviews (SRs) and meta-analyses (MAs) [62, 63]. A SR by Tsai et al., focused on weight-loss programs across the USA, saw $15.0-25.0 \%$ excess body weight loss over $3-$ 6 months, although fewer than $9.0 \%$ of the patients maintained their weight loss at 12 months [62]. In a MA by Dansinger et al. of 46 trials that provided dietary counseling, BMI was reduced by 1.9 units at 1 year (comparable to the 1.6 BMI units lost by the conventional therapy group in the current meta-analysis), with a per-month BMI loss of approximately 0.1 unit between 3 and 12 months of the active counseling programs, with a BMI regain of approximately 0.02-0.03 unit per month during follow-on maintenance phases [63].

Interestingly, while excluded from the current analysis, a 2005 comparative study, by Ritt et al., of 24 LAGB vs 16 conventional therapy patients reported an atypically large EWL (54.5 \%) [64], well outside the mean EWL (11.3 \%) for conventional therapy patients reported in our review. Also, in a 2007 OS by Anderson et al. of 1,531 morbidly obese conventional weight-loss patients with long-term follow-up employing very intensive behavioral intervention (e.g., weight-loss camps, residential nursing programs, and closely supervised individualized outpatient programs, possibly cost prohibitive for many patients), marked weight loss was achieved up to $100 \mathrm{lbs}$ over the short term; however, over 1-5-year follow-up, most patients regained 34.0-41.0\% of their lost weight [65].

\section{Bariatric Surgery}

The current findings for bariatric surgery in relation to BMI reduction (WMD, $\left.11.4 \mathrm{~kg} / \mathrm{m}^{2}[10.0,12.9]\right)$ and EWL $(75.3 \%$ [57.2-94.6]) were similar to those of two SR/MAs of the bariatric literature by Buchwald et al. [5, 22]; aggregated weight outcomes in morbidly obese patients found $13.6 \mathrm{~kg} / \mathrm{m}^{2}$ $(12.9,14.3)$ and $14.2 \mathrm{~kg} / \mathrm{m}^{2}(13.2,15.1)$ BMI reduction, $64.7 \%$ (32.0-93.0) and 55.9\% $(54.1,57.8)$ EWL, respectively [5, 22]. Also, an SR by Gill et al. of T2DM patients who underwent sleeve gastrectomy (SG) with a mean 13 months of follow-up noted $47.0 \%$ EWL [66].

\section{Conventional Treatment vs Bariatric Surgery}

A rigorous 2009 Cochrane review by Colquitt et al. of mildly and morbidly obese patients both with and without diabetes found that over the short term, bariatric surgery achieved substantially greater weight loss than medical therapy [67], as was concluded also by Maggard-Gibbons et al., of mildly obese diabetic patients in their 2013 SR [68]. Padwal et al.'s 2011 SR/MA of 31 RCTs, in which bariatric surgery was compared with other bariatric surgery controls or standard care ( $n=2,619$; BMI 42.0-58.0) using network analysis, found conventional treatment significantly less effective than 
surgery over the short and intermediate terms. Padwal et al. also found an average BMI WMD of $8.35 \mathrm{~kg} / \mathrm{m}^{2}(2.4-11.4)$ in their subset comparative study of all surgery vs conventional therapy [69]. The current review's between-group BMI WMD was nearly identical $\left(8.3 \mathrm{~kg} / \mathrm{m}^{2}[7.0,9.6]\right)$ to the results of Padwal et al., which would be expected since the current authors grouped procedures for analysis. In addition, the pooled adjusted SMD (corresponding to the BMI WMD of $8.3 \mathrm{~kg} / \mathrm{m}^{2}$ ) was $1.95(1.76,2.15)$, indicating that the average surgery patient experienced a BMI outcome superior to that of $97.1 \%$ of the conventional therapy group. While both treatment groups in the current review can be said to have experienced a statistically significant within-group BMI change, only the bariatric surgery patients experienced a clinically meaningful weight reduction, as demonstrated by a mean shift downward by as much as two obesity classifications.

\section{Diabetes}

\section{Conventional Treatment}

The long-running Look AHEAD study of weight loss by conventional treatment ( $n=5,145$ overweight adults with T2DM) found an association between intensive weight-loss intervention (ILI) and a reduction in T2DM markers: Mean $\mathrm{HbA}_{1 \mathrm{C}}$ dropped from 7.25 to $6.61 \%(p<0.00)$. Although the degree of success in ILI diabetes reduction experienced in the Look AHEAD study resulted in a seemingly greater outcome than that of the current meta-analysis, the Look AHEAD ILI group started at a lower $\mathrm{HbA}_{1 \mathrm{C}}$ than the conventional group in the current analysis, and their overall $\mathrm{HbA}_{1 \mathrm{C}}$ reduction was proportionally similar. By this measure, Look AHEAD results suggest that this form of therapy might be appropriate to those patients hovering around the $7.0 \% \mathrm{HbA}_{1 \mathrm{C}}$ mark at baseline. Look AHEAD FPG outcomes for the ILI group dropped from 151.9 to $130.4 \mathrm{mg} / \mathrm{dL}$, and were essentially identical to those of the conventional group in the current analysis [70]; the FPG reduction of the current analysis compared favorably, 143.1 to $123.2 \mathrm{mg} / \mathrm{dL}$.

\section{Bariatric Surgery}

The current meta-analytic findings for overall T2DM remission $(63.5 \%$ [38.2-100.0]) and FPG reduction of $34.5 \%$ (down to $95.3 \mathrm{mg} / \mathrm{dL}$ ) after bariatric surgery are similar to those of a 2011 cross-sectional nRCT by Reed et al., in which bariatric surgery patients were observed prior to and at 1 week and 3 months following RYGB; FPG decreased to levels similar to those $(\leq 125 / \mathrm{mg} / \mathrm{dL})$ of lean controls $(\mathrm{BMI} \leq 25)$, and diabetes was considered resolved [71]. In the aforementioned SR of T2DM SG patients by Gill et al., a rate of $66.0 \%$ remission was recorded [66], similar to our findings for the bariatric surgery group (63.5\%). In the 2004 SR/MA by
Buchwald et al., diabetes was completely resolved in $76.8 \%$ of bariatric surgery patients [5]; in the same authors' 2009 SR/ MA that focused on T2DM outcomes in 103 treatment arms $(n=3,188)$, at 2 -year post bariatric surgery, complete diabetes resolution (defined therein as normal FPG and no anti-diabetic medications) was attained by $78.1 \%$; at $\geq 2$ years, $74.6 \%$ continued resolved [22]. An MA of low-BMI bariatric surgery patients by $\mathrm{Li}$ et al. reported a significant mean decrease in $\mathrm{HbA}_{1 \mathrm{C}}$ of $2.59 \%$ in $80.0 \%$ of patients after surgery, consonant with the decrease found in our meta-analysis $(2.0 \%[1.2,2.8])[72]$.

\section{Conventional Treatment vs Bariatric Surgery}

The overall T2DM remission rates for surgery patients vs conventional therapy patients presented in the current analysis were significantly different, 63.5 vs $15.6 \%(p<0.001)$, respectively. The relative efficacy of bariatric surgery and conventional therapy in promoting T2DM remission was further quantified in the meta-analytic calculation of PORs based on 16 studies, $94.0 \%$ of which demonstrated a distinct statistical advantage in favor of bariatric surgery. When the analysis was run excluding trials reporting no remission events (which tend to produce inflated ORs), the summary point estimates were Peto POR of 6.9 (4.1, 11.6; inverse variance, 9.4 [5.0, 17.7], $p<0.001 ; I^{2}=75.4 \%$ ), still indicative of a large effect size favoring surgery. A second sensitivity analysis indicated that the odds of RYGB patients reaching T2DM remission were 8.0 times those of patients treated conventionally.

Remission event data were supported by parallel clinical evidence of T2DM remission in the form of $\mathrm{HbA}_{1 \mathrm{C}}$ outcome data. The pooled adjusted SMD quantifying the relative treatment effects of surgery vs conventional therapy on $\mathrm{HbA}_{1 \mathrm{C}}$ was $1.37(1.01,1.72)$, indicating that the average surgery patient experienced an $\mathrm{HbA}_{1 \mathrm{C}}$ outcome superior to that of $90.9 \%$ of the conventional therapy group. RCT and OS study surgery patients experienced both statistically and clinically significant reduction in $\mathrm{HbA}_{1 \mathrm{C}}$, moving from baseline levels of 8.9 and $7.6 \%$, respectively, to $6.1 \%$, well below the ADA target of $\leq 7.0 \%$. Conventional therapy patients also experienced a statistically significantly reduction in $\mathrm{HbA}_{1 \mathrm{C}}$ relative to baseline; however, whether participating in an RCT or OS, this group continued to experience poor glycemic control $(\geq 7.0 \%)$ at follow-up. Glycated hemoglobin is a primary clinical marker and predictor of T2DM. Diabetic patients have an $11.0 \%$ increased risk of mortality [73] from ischemic heart disease and, those with an $\mathrm{HbA}_{1 \mathrm{C}}>8 \%$ are subject to a $150.0 \%$ increased risk of death from heart disease [74]. Further, each $1.0 \%$ increase in $\mathrm{HbA}_{1 \mathrm{C}}$ has been shown to be associated with a $20.0-30.0 \%$ increase in cardiovascular events, and all-cause mortality independent of diabetes status [75].

The future will offer additional comparative evidence from high-quality, experimental studies of diabetes remission 
following bariatric surgery vs conventional treatment. A mid2013 publication describes the start of a well-designed multicenter RCT of lower-BMI insulin-dependent patients who will undergo RYGB plus standard medical treatment, if needed, compared with controls who will receive only standard T2DM treatment; this RCT, the DiaSurg Trial, with a target size of 400 participants, will provide long-term comparative data (8 years) on T2DM outcomes following bariatric surgery vs conventional diabetes care [76].

\section{Glycemic Control}

Two studies in the current comparative meta-analysis provide reason to believe that the marked improvement in glycemic control following bariatric surgery is not only more pronounced than with conventional therapy, but more durable over the long term. Sjöström et al. reported a $96.0 \%$ reduction in the risk of developing T2DM and a $36.0 \%$ rate of T2DM remission maintenance in bariatric surgery patients at 10 -year follow-up vs an increase in T2DM incidence in the usual care patient population [41]. Similarly, Iaconelli et al. reported $100.0 \%$ prolongation of T2DM remission at 10 -year followup vs $45.0 \%$ in the medical therapy group [48]. In addition, a recently published follow-up report of the original, included, O'Brien et al. study [77] shows sustained weight loss and metabolic syndrome resolution after 10 years. All three of these long-term findings support those of Pories et al., who found $>80.0 \%$ improvement in T2DM maintained at 14 years post surgery [14], and of Li et al., whose MA of patients with $<35$ BMI showed several patients in whom diabetes resolution was maintained at 18 years following surgery [72].

\section{Treating Lower-BMI Diabetic Patients}

Multiple SR/MAs reveal a gradation in diabetes resolution with specific bariatric operations, wherein the greatest effect is associated with malabsorptive procedures, BPD and DS $(95.0-98.9 \%)$ [5, 22]. Yet, $90.0 \%$ of T2DM patients are not morbidly obese [78-80]. The hypothesis of metabolic surgery-that certain procedures, some bariatric, performed without a primary weight-loss focus, but rather with the goal of achieving improved control or remission of diseases such as diabetes - has now been examined in several OSs, nRCTs, and RCTs [15, 58, 69, 81]. In our 2010 systematic review and integrative analysis of studies of metabolic surgery between 1979 and 2009 for treatment of T2DM in 343 patients with BMI $<35$, we reported $85.3 \%$ T2DM resolution based on an FPG reduction of $93.3 \mathrm{mg} / \mathrm{dL}(105.2 \mathrm{mg} / \mathrm{dL},-93.3)$ with patients off antidiabetic medications, and an $\mathrm{HbA}_{1 \mathrm{C}}$ reduction of $2.7 \%$ into the normal range $(<6.0 \%)$ in addition to significant, not excessive, BMI loss of 5.1 (from 29.4 to 24.2) [15]. In a later review by Reis et al. that included our SR's original 16 papers in addition to several additional more recently published studies, very similar results were found for patients with $\mathrm{BMI}<35$ [82].

The current meta-analytic findings relevant to treating lower-BMI diabetic patients showed no significant heterogeneity between low- and high-BMI subgroups in summary estimates quantifying the relative effects of bariatric surgery vs conventional therapy on T2DM remission. The high-BMI $(\mathrm{BMI} \geq 35)$ and lower-BMI $(\mathrm{BMI}<35)$ subgroups had respective PORs of $15.2(6.8,34.1)$ and $17.1(4.7,62.9)$. This suggests that lower-BMI patients may also be able to experience the T2DM-reduction benefits of bariatric surgery long observed in higher-BMI patients.

Patients whose diabetes may be treated more effectively by bariatric surgery than conventional therapy, as found in the current meta-analysis that sought patients with a BMI $\geq 25$, may benefit from the opportunity to elect T2DM treatment by surgery. The 2009 Asian Indian Consensus Statement, for example, recommended lowering the BMI cutoff for bariatric surgery with a comorbidity to 32.5 [83], making surgical treatment for diabetes available to more patients who, because of their ethnicity, may develop severe disease at lower weights than Caucasians [84]. Also, the 2011 International Diabetes Federation (IDF) Task recommendation for clinical practice as it relates to T2DM suggested that bariatric surgery should be considered an appropriate treatment under certain circumstances, including failure of conventional weight and T2DM therapy to control diabetes in those with a BMI of 30-35 [85]. Currently, however, the US National Institutes of Health $(\mathrm{NIH})$ guidelines for bariatric surgery for patients with one or more comorbidity stipulate a BMI cutoff of $\geq 35$, as do the Centers for Medicare and Medicaid Services (CMS), who maintain their 2006 policy of bariatric surgery approval only for patients with a $\mathrm{BMI} \geq 35[59,86]$.

\section{Limitations}

Only the available literature can be evaluated by a systematic review. The analytic power of this review was limited due to the diversity of T2DM diagnosis and remission standards reported. Most studies determined T2DM outcomes idiosyncratically; the majority of studies did not define T2DM remission uniformly, some employing ADA or $\mathrm{NIH}$ measures, and others, only biochemical marker of glycemic control. Although the number of available RCTs was noteworthy, representing almost one third of included studies, there is a shortage of well-controlled observational and level 1 (experimental) evidence comparing bariatric surgery and conventional therapy outcomes; a greater number of welldesigned experimental studies would have increased this review's predictive strength. A uniform standard for reporting T2DM remission is needed to improve the scientific evidence base and support clinical decision making. Another limitation of the analysis was that three studies, included because they 
met all comparative study requirements, incorporated conventional therapy arms that included no patient treatment, and simply followed patients who received no focused weight-loss intervention as a measure of "conventional treatment".

Another possible limitation of this study was the use of standard deviation imputation in order to allow for inclusion of reported mean data that were not accompanied by variance data. In an effort to assess imputation bias, parallel analyses of between-group outcomes were carried out, incorporating into the meta-analyses only those studies with complete data, as originally abstracted. Without exception, imputation was shown to slightly constrain effect size. Also, the grouping of bariatric procedures may have introduced bias; however, sensitivity analysis demonstrated that the grouping technique, as applied in this research, also served to constrain effect size. Thus, SMDs reported herein likely represent relatively conservative summary estimates. Finally, our analyses afforded mainly short-term results: Comparative data for weight and T2DM remission in bariatric surgery vs conventional therapy at follow-up time points greater than 17.3 months are needed.

\section{Conclusions}

The current research summarizes the best available findings for weight loss and T2DM remission in directly comparative research studies of surgery vs medical therapy in mildly obese, obese, and morbidly obese patients, a treatment effect corroborated by the analysis of $\mathrm{HbA}_{1 \mathrm{C}}$ reduction. The current review demonstrates that surgery has a dramatically greater weightloss effect, by $\geq 3$ orders of magnitude, and a more expeditious and higher rate of T2DM remission than conventional therapy.

Physicians must appraise the evidence for bariatric surgery vs conventional therapy on a patient-by-patient basis, weighing complications and costs associated with surgery against those associated with uncontrolled T2DM and/or comorbid obesity. However, only $1.0-3.0 \%$ of individuals who reach class I obesity ever return to normal weight through conventional means [87], and a significant proportion of them go on to develop T2DM. Thus, the current meta-analytic finding, that the effectiveness of treatment with bariatric surgery far exceeds that of conventional therapy, carries the additional implication that surgery should be considered as a preventive measure.

In this systematic review and meta-analysis of 16 comparative studies of 6,131 patients with a baseline BMI ranging from 30.2 to 51.5 at mean 17-month follow-up, bariatric surgery was significantly more effective in achieving weight loss, $\mathrm{HbA}_{1 \mathrm{C}}$ reduction, and diabetes remission than conventional medical therapy. Based on overall summary estimates, the odds of T2DM remission in patients undergoing bariatric surgery were calculated to be from 9.8 to 15.8 times the odds of remission for those patients receiving conventional therapy, a finding that held true regardless of study design, severity of
T2DM (as measured by baseline $\mathrm{HbA}_{1 \mathrm{C}}$ ), preoperative BMI, age, or weight loss.

Disclosure G. Ribaric is Head of Clinical and Medical Affairs at Ethicon Endo-Surgery Europe, GmBH, a subsidiary of Johnson \& Johnson. J.N. Buchwald is Director and Chief Scientific Research Writer at Medwrite LLC, Wisconsin, USA, and T.W. McGlennon is Director, Statistical Analysis and Quality of Life Assessment, McGlennon MotiMetrics (M3), Wisconsin, USA, both CROs under contract with Ethicon. The study was financially supported by Ethicon Endo-Surgery Europe, GmBH.

Open Access This article is distributed under the terms of the Creative Commons Attribution License which permits any use, distribution, and reproduction in any medium, provided the original author(s) and the source are credited.

\section{References}

1. Sims EH et al. Endocrine and metabolic effects of experimental obesity in man. Recent Prog Horm Res. 1973;29:457-96.

2. World Health Organization. Obesity and overweight - fact sheet No. 311. Updated March 2013. Accessed June 11, 2013: http://www. who.int/mediacentre/factsheets/fs311/en/index.html

3. World Health Organization. Obesity and overweight — fact sheet no. 312. Updated March 2013. http://www.who.int/mediacentre/ factsheets/fs312/en/. Accessed 11 June 2013

4. Andersson C, van Gaal L, Caterson ID, et al. Relationship between $\mathrm{HbA}_{1 \mathrm{C}}$ levels and risk of cardiovascular adverse outcomes and all-cause mortality in overweight and obese cardiovascular high-risk women and men with type 2 diabetes. Diabetologia. 2012;55(9):2348-55.

5. Buchwald $\mathrm{H}$, Avidor Y, Braunwald E, et al. Bariatric surgery: a systematic review and meta-analysis. JAMA. 2004;292:1724-37.

6 . The Surgeon General's call to action to prevent and decrease overweight and obesity/ Office of Disease Prevention and Health Promotion; Centers for Disease Control and Prevention, National Institutes of Health. [Rockville, MD]: U.S. Dept. of Health and Human Services, Public Health Service, Office of the Surgeon General; Washington, D.C., 2001.

7. Resnick HE, Foster GL, Beardsley J, et al. Achievement of American Diabetes Association clinical practice recommendations among U.S. adults with diabetes, 1999-2002: the National Health and Nutrition Examination Survey. Diabetes Care. 2006;29:531-7.

8. Garber A, Henry R, Ratner R, et al. Liraglutide versus glimepiride monotherapy for type 2 diabetes (LEAD-3 MONO): randomized, 52-week, phase III, double blind, parallel-treatment trial. Lancet. 2009;373:473-81.

9. Wong K, Glovaci D, Malik S, et al. Comparison of demographic factors and cardiovascular risk factor control among US adults with type 2 diabetes by insulin treatment classification. J Diabetes Complicat. 2012;26(3):169-74.

10. Sjöström L. Review of the key results from the Swedish Obese Subjects (SOS) trial - a prospective controlled intervention study of bariatric surgery. J Intern Med. 2013;273(3):219-34.

11. Nguyen N, Champion JK, Ponce J, et al. A review of unmet needs in obesity management. Obes Surg. 2012;22(6):956-66.

12. Christiansen T, Brunn JM, Madsen EL, et al. Weight loss maintenance in severely obese adults after an intensive lifestyle intervention: 2- to 4-year follow-up. Obesity. 2007;15(2):413-20.

13. Goodrick GK, Foreyt JP. Why treatments for obesity don't last. JAMA. 1991;91:1243-7. 
14. Pories WJ, Swanson MS, MacDonald KG, et al. Who would have thought it? An operation proves to be the most effective therapy for adult-onset diabetes mellitus. Ann Surg. 1995;222:339-50.

15. Fried M, Ribaric G, Buchwald JN. Metabolic surgery for the treatment of type 2 diabetes in patients $<35 \mathrm{~kg} / \mathrm{m}^{2}$ : an integrative review of early studies. Obes Surg. 2012;20(6):776-90.

16. Scopinaro N, Papadia F, Marinari G, et al. Long-term control of type 2 diabetes mellitus and the other major components of the metabolic syndrome after biliopancreatic diversion in patients with BMI $<35 \mathrm{~kg} / \mathrm{m}^{2}$. Obes Surg. 2007;17:185-92.

17. Ritter S, Vetter ML, Sarwer DB. Lifestyle modifications and surgical options in the treatment of patients with obesity and type 2 diabetes mellitus. Postgrad Med. 2012;124(4):168-80.

18. Abbatini F, Capoccia D, Casella G, et al. Type 2 diabetes in obese patients with body mass index of $30-35 \mathrm{~kg} / \mathrm{m}^{2}$ : sleeve gastrectomy versus medical treatment. Surg Obes Relat Dis. 2012;8(1):20-4.

19. Laferrere B, Teixeira J, McGinty J, et al. Effect of weight loss by gastric bypass surgery versus hypocaloric diet on glucose and incretin levels in patients with type 2 diabetes. J Clin Endocrinol Metab. 2008;93:2479-85.

20. Shaw JE, Sicree RA, Zimmet PZ. Global estimates of the prevalence of diabetes for 2010 and 2030. Diabetes Res Clin Pract. 2010;87:4 14.

21. Dixon JB, le Roux CW, Rubino F, et al. Bariatric surgery for type 2 diabetes. Lancet. 2012;379:2300-11.

22. Buchwald H, Estok R, Fahrbach K, et al. Weight and type 2 diabetes after bariatric surgery: systematic review and meta-analysis. Am J Med. 2009;122(3): 248-56-e5.

23. Spann SJ, Nutting PA, Galliher JM, et al. Management of type 2 diabetes in the primary care setting: a practice-based research network study. Ann Fam Med. 2006;4:23-31.

24. American Diabetes Association. Standards of medical care in diabetes-2009. Diabetes Care. 2009;33 Suppl 1:S11-61.

25. le Roux CW, Welbourn R, Werling M. Gut hormones as mediators of appetite and weight loss after Roux-en-Y gastric bypass. Ann Surg. 2007;246:780-5.

26. Cummings DE, Overduin J, Foster-Schubert K-E. Gastric bypass for obesity: mechanisms of weight loss and diabetes resolution. J Clin Endocrinol Metab. 2004;89:2608-15.

27. Cummings DE, Shannon MH. Ghrelin and gastric bypass: is there a hormonal contribution to surgical weight loss? J Clin Endocrinol Metab. 2003;88:2999-3002.

28. Rubino F, Forgione A, Cummings DE, et al. The mechanism of diabetes control after gastrointestinal bypass surgery reveals a role of the proximal small intestine in the pathophysiology of type 2 diabetes. Ann Surg. 2006;244:741-9.

29. Pories WJ, Caro JF, Flickinger EG, et al. The control of diabetes mellitus (NIDDM) in the morbidly obese with the Greenville gastric bypass. Ann Surg. 1987;206:316-23.

30. Guidone C, Manco M, Valera-Mora E, et al. Mechanisms of recovery from type 2 diabetes after malabsorptive bariatric surgery. Diabetes. 2006;55:2025-31.

31. MacDonald KG, Long SD, Swanson MS. The gastric bypass operation reduces the progression and mortality of noninsulin-dependent diabetes mellitus. J Gastrointest Surg. 1997;1:213-20.

32. Cummings DE, Overduin J, Shannon MH. Hormonal mechanisms of weight loss and diabetes resolution after bariatric surgery. Surg Obes Relat Dis. 2005;1:358-68.

33. Astiarraga B, Gastaldelli A, Muscelli E, et al. Biliopancreatic diversion in nonobese patients with type 2 diabetes: impact and mechanisms. J Clin Endocrinol Metab. 2013;98(7):2765-73.

34. Oxford Centre for Evidence-Based Medicine. http://www.cebm.net/ index.aspx?o=5653. Accessed 30 March 2013.

35. Moher D, Liberati A, Tetzlaff J, et al. Preferred reporting items for systematic reviews and meta-analyses: The PRISMA Statement. PLoS Med. 2009;6(6):e1000097.
36. North American Association for the Study of Obesity (NAASO) and the National Heart, Lung, and Blood Institute (NHLBI). The practical guide: identification, evaluation, and treatment of overweight and obesity in adults. NIH Publication \#00-4084, October 2000.

37. Duriak J. How to select, calculate, and interpret effect sizes. J Pediatr Psychol. 2009;34(9):917-28.

38. Furukawa TA, Barbui C, Cipriani A, et al. Imputing missing standard deviation in meta-analyses can provide accurate results. J Clin Epidemiol. 2006;59:7-10.

39. Higgins JP, Thompson SG, Deeks JJ, et al. Measuring inconsistency in meta-analyses. BMJ. 2003;327:557-60.

40. Shikata S, Nakayama S, Yamagishi H. Comparison of effects in randomized controlled trials with observational studies in digestive surgery. Ann Surg. 2006;244(5):668-76.

41. Sjöström L, Lindroos AK, Peltonen M, et al. Lifestyle, diabetes, and cardiovascular risk factors 10 years after bariatric surgery. N Engl J Med. 2004;351(26):2683-93.

42. O'Brien PE, Dixon JB, Laurie C, et al. Treatment of mild to moderate obesity with laparoscopic adjustable gastric banding or an intensive medical program. A randomized trial. Ann Intern Med. 2006;144: 625-33.

43. Dixon JB, O’Brien PE, Playfair J, et al. Adjustable gastric banding and conventional therapy for type 2 diabetes: a randomized controlled trial. JAMA. 2008;299(3):316-23.

44. Hofs $\varnothing$ D, Nordstrand N, Johnson LK, et al. Obesity-related cardiovascular risk factors after weight loss: a clinical trial comparing gastric bypass surgery and intensive lifestyle intervention. Eur J Endocrinol. 2010;163(5):735-45.

45. Adams TD, Pendleton RC, Strong MB, et al. Health outcomes of gastric bypass patients compared to nonsurgical, nonintervened severely obese. Obesity (Silver Spring). 2010;18(1):121-30.

46. Serrot FJ, Dorman RB, Miller CJ, et al. Comparative effectiveness of bariatric surgery and nonsurgical therapy in adults with type 2 diabetes mellitus and body mass index $<35 \mathrm{~kg} / \mathrm{m}^{2}$. Surgery. 2011;150(4):684-91.

47. Martins C, Strømmen M, Stavne OA, et al. Bariatric surgery versus lifestyle interventions for morbid obesity - changes in body weight, risk factors and comorbidities at 1 year. Obes Surg. 2011;21(7):84-9.

48. Iaconelli A, Panunzi S, De Gaetano A, et al. Effects of biliopancreatic diversion on diabetic complications: a 10-year followup. Diabetes Care. 2011;34(3):561-7.

49. Scopinaro N, Adami GF, Papadia FS, et al. Effects of biliopanceratic diversion on type 2 diabetes in patients with BMI 25 to 35 . Ann Surg. 2011;253(4):699-703.

50. Leonetti F, Capoccia D, Coccia F, et al. Obesity, type 2 diabetes mellitus, and other comorbidities: a prospective cohort study of laparoscopic sleeve gastrectomy vs medical treatment. Arch Surg. 2012;147(8):694-700.

51. Mingrone G, Panunzi S, De Gaetano A, et al. Bariatric surgery versus conventional medical therapy for type 2 diabetes. $N$ Engl J Med. 2012;366(17):1577-85.

52. Heo YS, Park JM, Kim YJ, et al. Bariatric surgery versus conventional therapy in obese Korea patients: a multicenter retrospective cohort study. J Korean Surg Soc. 2012;83(6):335-42.

53. Dorman RB, Serrot FJ, Miller CJ, et al. Case-matched outcomes in bariatric surgery for treatment of type 2 diabetes in the morbidly obese patient. Ann Surg. 2012;255(2):287-93.

54. Leslie DB, Dorman RB, Serrot FJ, et al. Efficacy of the Roux-en-Y gastric bypass compared to medically managed controls in meeting the American Diabetes Association composite end point goals for management of type 2 diabetes mellitus. Obes Surg. 2012;22(3):367-74.

55. Schauer PR, Kashyap SR, Wolski K, et al. Bariatric surgery versus intensive medical therapy in obese patients with diabetes. N Engl J Med. 2012;366(17):1567-76.

56. Ikramuddin S, Korner J, Lee W-J, et al. Roux-en-Y gastric bypass vs intensive medical management for the control of type 2 diabetes, 
hypertension, and hyperlipidemia: The Diabetes Surgery Study Randomized Clinical Trial. JAMA. 2013;309(21):2240-9.

57. Buchwald H, Oien D. Metabolic/bariatric surgery worldwide 2011. Obes Surg. 2013;23:427-36.

58. Shukla AP, Moreira M, Dakin G, et al. Medical versus surgical treatment of type 2 diabetes: the search for level 1 evidence. Surg Obes Relat Dis. 2012;8(4):476-82.

59. No authors listed. Gastrointestinal Surgery for Severe Obesity. Consen Statement 1991; 9(1):1-20.

60. Fried M, Hainer V, Basdevant A, et al. Inter-disciplinary European guidelines on surgery of severe obesity. Int J Obes (Lond). 2007;31(4):569-77.

61. Shrier I, Boivin J-F, Steele RJ, et al. Should meta-analyses of interventions include observational studies in addition to randomized controlled trials? A critical examination of underlying principles. Am J Epidemiol. 2007;166:1203-9.

62. Tsai AG, Wadden TA. Systematic review: an evaluation of major commercial weight loss programs in the United States. Ann Intern Med. 2005;142:56-66.

63. Dansinger ML, Tabsioni A, Wong JB, et al. Meta-analysis: the effect of dietary counseling for weight loss. Ann Intern Med. 2007;147(1): 41-50.

64. Ritt M, Piza H, Rhomberg M, et al. Metabolic risk factors in formerly obese women - effects of a pronounced weight loss by gastric band operation compared with weight loss by diet alone. Diabetes Obes Metab. 2005;7(3):216-22.

65. Anderson JW, Grant L, Gotthelf L, et al. Weight loss and long-term follow-up of severely obese individuals treated with an intense behavioral program. Int J Obes. 2007;31(3):488-93.

66. Gill RS, Birch DW, Shi X, et al. Sleeve gastrectomy and type 2 diabetes mellitus: a systematic review. Surg Obes Relat Dis. 2010;6: 707-13.

67. Colquitt JL, Picot J, Loveman E, et al. Surgery for obesity. Cochrane Database Syst Rev 2009; CD003641.

68. Maggard-Gibbons M, Maglione M, Livhits M, et al. Bariatric surgery for weight loss and glycemic control in nonmorbidly obese adults with diabetes: a systematic review. JAMA. 2013;309(21):2250-61.

69. Padwal R, Klarenbach S, Wiebe N, et al. Bariatric surgery: a systematic review and network meta-analysis of randomized medical versus surgical treatment of type 2 diabetes: the search for level 1 evidence. Obes Rev. 2011;12:602-21.

70. Gregg EW, Chen H, Wagenknecht LE, et al. for the Look AHEAD Research Group. Association of an intensive lifestyle intervention with remission of type 2 diabetes. JAMA. 2012;308(23):2489-96.

71. Reed MA, Pories WJ, Chapman W, et al. Roux-en-Y gastric bypass corrects hyperinsulinemia implications for the remission of type 2 diabetes. J Clin Endocrinol Metab. 2011;96(8):2525-31.

72. Li Q, Chen L, Yang Z, et al. Metabolic effects of bariatric surgery in type 2 diabetic patients with body mass index $<35 \mathrm{~kg} / \mathrm{m}^{2}$. Diabetes, Obes Metab. 2012;14:262-70.

73. Turner RC, Mill NSH, Haw N, et al. Risk factors for coronary artery disease in non-insulin dependent diabetes mellitus: United Kingdom prospective diabetes study. BMJ. 1998;339:229-34.
74. Saydah S, Tao M, Imperatore G, et al. GHb level and subsequent mortality among adults in the US. Diabetes Care. 2009;32:1440-6.

75. Khow KT, Warham N, Bingham S, et al. Association of haemoglobin A1c with cardiovascular disease and mortality in adults: the European prospective investigation into cancer in Norfolk. J Ann Intern Med. 2004;141:413-20.

76. Kenngott HG, Clemens G, Gondan M, et al. DiaSurg 2 trialsurgical vs. medical treatment of insulin-dependent type 2 diabetes mellitus in patients with a body mass index between 26 and $35 \mathrm{~kg} / \mathrm{m}^{2}$ : study protocol of a randomized controlled multicenter trial. Trials. 2013;14(1):183.

77. O’Brien PE, Brennan L, Laurie C, et al. Intensive medical weight loss or laparoscopic adjustable gastric banding in the treatment of mild to moderate obesity: long-term follow-up of a prospective randomized trial. Obes Surg. 2013;23:1345-53.

78. Mokdad AH, Ford ES, Bowman BA, et al. Prevalence of obesity, diabetes and obesity-related health risk factors, 2001. JAMA. 2003;289:76-9.

79. Mokdad AH, Bowman BA, Ford ES, et al. The continuing epidemics of obesity and diabetes in the United States. JAMA. 2001;286:1195200.

80. North American Association for the Study of Obesity (NAASO) and the National Heart. Clinical Guide lines on the identification, evaluation, and treatment of overweight and obesity in adults: the evidence report. Bethesda, MD: National Institutes of Health; 1998. NIH publication 98-4083.

81. Rubino F, Schauer PR, Kaplan LM, et al. Metabolic surgery to treat type 2 diabetes: clinical outcomes and mechanisms of action. Annu Rev Med. 2010;61:393-411.

82. Reis CEG, Alvarez-Leite JI, Bressan J, et al. Role of bariatricmetabolic surgery in the treatment of obese type 2 diabetes with body mass index $<35 \mathrm{~kg} / \mathrm{m}^{2}$ : a literature review. Diabetes Technol Ther. 2012;14(4):365-72.

83. Misra A, Chowbey P, Makkar BM, et al. Consensus statement for diagnosis of obesity, abdominal obesity and the metabolic syndrome for Asian Indians and recommendations for physical activity, medical and surgical management. J Assoc Phys India. 2009;57:163-70.

84. Razak F, Anand SS, Shannon H, et al. Defining obesity cut points in a multiethnic population. Circulation. 2007;115:2111-8.

85. Dixon JB, Zimmet P, Alberti KG, et al. on behalf of the International Diabetes Federation Taskforce on Epidemiology and Prevention. Bariatric surgery: an IDF statement for obese type 2 diabetes. Diabet Med. 2011;28:628-42.

86. Centers for Medicare and Medicaid Services. Decision Memo for Surgery for Diabetes (CAG-00397 N). http://www.cms.gov/ medicare-coverage-database/details/nca-decision-memo.aspx? NCAId $=219 \&$ NcaName $=$ Surgery + for + Diabetes $\& N C D I d=$ $326 \&$ ncdver $=1 \&$ IsPopup $=y \& b c=$ AAAAAAAACAAAAA $\% 3 \mathrm{D} \%$ 3D\&. Accessed on 10 July 2013.

87. Finkelstein EA, Øsbye T, Malhotra R. Body mass trajectories through mid-life among adults with class-I obesity. Surg Obes Relat Dis. 2013;9:547-53. 